\title{
Excitatory Amino Acid Transporters of the Salamander Retina: Identification, Localization, and Function
}

\author{
Scott Eliasof, ${ }^{1}$ Jeffrey L. Arriza, ${ }^{1}$ Barbara H. Leighton, ${ }^{2}$ Michael P. Kavanaugh, ${ }^{1}$ and Susan G. Amara ${ }^{1,2}$ \\ ${ }^{1}$ Vollum Institute and ${ }^{2}$ Howard Hughes Medical Institute, Oregon Health Sciences University, Portland, Oregon 97201
}

The rapid re-uptake of extracellular glutamate mediated by a family of high-affinity glutamate transporter proteins is essential to continued glutamatergic signaling and neuronal viability, but the contributions of individual transporter subtypes toward cellular physiology are poorly understood. Because the physiology of glutamate transport in the salamander retina has been well described, we have examined the expression and function of glutamate transporter subtypes in this preparation. cDNAs encoding five distinct salamander excitatory amino acid transporter (sEAAT) subtypes were isolated, and their molecular properties and distributions of expression were compared. We report evidence that at least four distinct sEAAT subtypes are expressed in glial (Müller) cells. In addition, four of the five transporter subtypes are localized in neurons throughout the retina. The brightest immunostaining was seen in the synaptic regions of the inner and outer plexiform layers and in the outer nuclear layer. Using electrophysiological measurements in the Xenopus oocyte expression system, we also examined the pharmacology and ionic dependence of the four expressing transporter subtypes that make it possible to distinguish, on the basis of functional behavior, among the various subtypes. Although no simple correlation between transporter subtype and retinal cell physiology can be made, the diverse population of sEAAT transporter subtypes with unique localization and functional properties indicates that glutamate transporters play a wide variety of roles in retinal function and are likely to underlie both the uptake of glutamate by Müller cells and the glutamateelicited chloride conductance involved in signal transduction by photoreceptors and bipolar cells.

Key words: glutamate transporter; uptake; amino acid; retina; chloride; molecular cloning; photoreceptors; Müller cells; bipolar cells; immunohistochemistry
Glutamate is the predominant excitatory neurotransmitter in the vertebrate retina and is released from photoreceptors, bipolar cells, and ganglion cells (for review, see Massey, 1990). Termination of glutamatergic synaptic transmission requires uptake of glutamate by means of plasma membrane glutamate transporters, which may be present presynaptically and postsynaptically as well as in neighboring glial cells. These transporters are of particular importance in the retina, where glutamate is released continuously and at a high rate in the dark.

Electrophysiological studies performed primarily in the salamander retina have demonstrated the existence of glutamate transporters in retinal glial (Müller) cells (Brew and Attwell, 1987; Schwartz and Tachibana, 1990), in photoreceptors (Tachibana and Kaneko, 1988; Eliasof and Werblin, 1993; Grant and Werblin, 1996), and in depolarizing bipolar cells (DBC; Grant and Dowling, 1995). These transporters are electrogenic and sodium-dependent; they possess pharmacological properties distinct from glutamate receptors. In addition, a measurable uncoupled flux of chloride ions associated with glutamate transport is present in all retinal cells transporting glutamate (Grant and Dowling, 1995; Picaud et al., 1995a; Billups et al., 1996; Eliasof and Jahr, 1996; Grant and Werblin, 1996). In the case of photo-

Received Aug. 28, 1997; revised Oct. 28, 1997; accepted Nov. 4, 1997.

This work was supported by National Institutes of Health Grants NS33270 (M.P.K.) and NS33273 (S.G.A.), a McKnight Investigator Award (S.G.A.), and the Howard Hughes Medical Institute (S.G.A.). We thank Jürgen Bolz for his comments on this manuscript, Eva Shannon and Lorene Langeberg for technical advice regarding confocal microscopy and affinity purification, respectively, and Craig Jahr for his support during the initial stages of this project.

Correspondence should be addressed to Dr. Susan Amara, Vollum Institute L-474, Oregon Health Sciences University, 3181 SW Sam Jackson Park Road, Portland, OR 97201.

Copyright (C) 1998 Society for Neuroscience $\quad 0270-6474 / 98 / 180698-15 \$ 05.00 / 0$ receptors and DBCs, this anionic current accounts for the majority of the total glutamate-elicited current and has been suggested to play an important role in the physiological responses of these cells (Sarantis et al., 1988; Grant and Dowling, 1995, 1996; Picaud et al., 1995b).

Recently, cDNAs encoding five mammalian excitatory amino acid transporter (EAAT) subtypes have been isolated, thereby permitting the characterization of their functions in heterologous expression systems and the determination of their anatomical distributions via subtype-specific probes and antisera. Human brain expresses the transporter subtypes EAAT1, EAAT2, and EAAT3 (Arriza et al., 1994) as well as EAAT4 (Fairman et al., 1995). EAAT5 is expressed specifically in the human retina and, like EAAT4 (Fairman et al., 1995), the transport of glutamate is associated with a large, intrinsic chloride conductance that accounts for most of the glutamate-elicited current (Arriza et al., 1997).

Immunocytochemical studies indicate that EAAT1, EAAT2, and EAAT3 are present in the rat retina (Rauen and Kanner, 1994; Derouiche and Rauen, 1995; Rauen et al., 1996; Lehre et al., 1997). However, EAATs 1, 2, and 3 possess only a modest chloride conductance (Wadiche et al., 1995), unlike photoreceptors and DBCs. Therefore, these three transporter subtypes are insufficient to explain the known physiology of glutamate transport in the vertebrate retina. The localization of EAATs 4 and 5 in the vertebrate retina has not yet been examined.

To ascertain further the molecular basis of physiological function, we have applied molecular biology techniques to identify five distinct glutamate transporters expressed in the salamander retina: sEAAT1, sEAAT2A, sEAAT2B, sEAAT5A, and sEAAT5B. Using immunocytochemical techniques, we have examined their cellular localization, and the functional properties of these trans- 
porter subtypes have been assessed with the Xenopus oocyte expression system. From our understanding of function and localization, we can begin to identify the different glutamate transporter subtypes that underlie the well described behavior of glutamate transporters in the salamander retina and their role in retinal function.

\section{MATERIALS AND METHODS}

cDNA synthesis, library preparation, and clone isolations. Retinas were dissected from larval stage tiger salamanders (Ambystoma tigrinum) obtained from Kons Scientific (Germantown, WI). Poly $\left(\mathrm{A}^{+}\right)$RNA was prepared from the retinas of 30 salamanders (150 mg wet weight), using the QuickPrep Micro mRNA purification kit according to the manufacturer's protocol (Pharmacia, Piscataway, $\mathrm{NJ}$ ) to obtain $\sim 4 \mu \mathrm{g}$ of mRNA. Double-stranded cDNA was prepared, using the Superscript Choice System (Life Technologies, Gaithersburg, MD) with both oligo-dT and random hexamer priming, ligated with EcoRI(SalI) adaptors, and sizefractionated. cDNA fractions sized $0.6 \mathrm{~kb}$ and larger were pooled $(\sim 200$ ng), and most of this material was used for the preparation of a cDNA library. The remainder $(\sim 10 \mathrm{ng})$ was used for PCR with degenerate oligonucleotides (see below). The salamander retina cDNA was ligated with $\lambda$ ZAPII arms and Gigapack Gold extracts used for packaging (Stratagene, La Jolla, CA). The resulting library, termed $\lambda$ SR, contained $1.7 \times 10^{6}$ independent clones: 700,000 clones were screened directly, while the remainder were amplified for long-term storage as 20 independent pools with 50,000 clones each.

Partial cDNA sequences for salamander glutamate transporter genes were isolated by PCR with degenerate oligonucleotide primers (see Table 1). Initial amplification of retinal cDNA used primers ATINMDG and AVDW(f/l)LD, with 25 cycles of $30 \mathrm{sec}$ at $94^{\circ} \mathrm{C}, 30 \mathrm{sec}$ at $50^{\circ} \mathrm{C}$, and $30 \mathrm{sec}$ at $72^{\circ} \mathrm{C}$. Products were purified with Magic PCR Preps (Promega, Madison, WI), and 1/100th of the reaction was used for a subsequent 25 cycles with primers AA(i/v)FIAQ and AVDW(f/l)LD under the same reaction conditions. After purification, products were digested with $B a m \mathrm{HI}$ and $X b a \mathrm{I}$, subcloned into Bam $\mathrm{HI} / X b a \mathrm{I}$-digested pBluescript (Stratagene), and sequenced to identify seven distinct cDNA products (see Fig. $1 A$ )

The $\lambda$ SR library was screened by using mixed human EAAT1 through EAAT3 (Arriza et al., 1994) coding sequence cDNA probes under reduced stringency conditions. Plaque filter lifts, prepared as per the manufacturer's instructions (GeneScreen, New England Nuclear, Boston, MA), were hybridized overnight at $55^{\circ} \mathrm{C}$ in $0.5 \mathrm{M} \mathrm{Na}_{2} \mathrm{HPO}_{4}, \mathrm{pH} 7.15,7 \%$ $\mathrm{SDS}$, and $1 \mathrm{~mm}$ EDTA, with the cDNA probe coding sequence ${ }^{32} \mathrm{P}$ radiolabeled by random priming and present at $1 \times 10^{6} \mathrm{cpm} / \mathrm{ml}$ (Boehringer Mannheim, Indianapolis, IN). Filters were washed at $55^{\circ} \mathrm{C}$ in $2 \times$ SSPE $\left(20 \times \operatorname{SSPE}=3 \mathrm{M} \mathrm{NaCl}, 0.2 \mathrm{M} \mathrm{NaH}_{2} \mathrm{PO}_{4}\right.$, and $0.02 \mathrm{M} \mathrm{Na}{ }_{2}$ EDTA, $\mathrm{pH} 7.4$ ) and $1 \%$ SDS. Clones corresponding to SR6, SR24, SR27, SR30, and SR72 were recovered by in vivo excision, and the complete coding sequences were determined from both strands by using a double-stranded template and an Applied Biosystems 373 Stretch DNA Sequencer (Foster City, CA). Sequence data analyses and comparisons were performed with MacVector (Kodak, Rochester, NY). The library was screened for clones corresponding to SR29 and SR32, using the partial salamander cDNAs, but no positives were obtained. In addition, the library was screened independently with EAAT3 and EAAT4 probes, but no library clones were obtained that correspond to human EAAT3 or EAAT4.

Oocyte expression. For expression of sEAAT subtypes in Xenopus oocytes, the coding sequence of each subtype cDNA was isolated by PCR, using sense-antisense primer pairs (see Table 1) and the following amplification conditions: 25 cycles of denaturation $\left(30 \mathrm{sec}\right.$ at $\left.94^{\circ} \mathrm{C}\right)$, annealing $\left(30 \mathrm{sec}\right.$ at $\left.55^{\circ} \mathrm{C}\right)$, and extension $\left(2 \mathrm{~min}\right.$ at $\left.72^{\circ} \mathrm{C}\right)$; these were performed in $100 \mu \mathrm{l}$ reactions that contained oligonucleotide primers at $1 \mu \mathrm{M}$ each, $10 \mathrm{ng}$ of plasmid cDNA template, $300 \mu \mathrm{M}$ each deoxynucleotide, Vent polymerase, and reaction buffer (New England Biolabs, Beverly, MA). Digestion of the reaction products with the indicated restriction enzymes allowed coding sequences to be subcloned into pOTV (Arriza et al., 1994). cRNA was prepared by transcribing the linearized vector, and $\sim 50 \mathrm{ng}$ of cRNA was microinjected into defolliculated stage V-VI oocytes 3-7 d before recording.

Northern blotting. Total RNA (20 $\mu \mathrm{g}$ per lane) prepared from salamander retinas was gel-electrophoresed as described, transferred to GeneScreen, and hybridized as previously described (Arriza et al., 1994) with subtype-selective probes. Hybridization probes were isolated from the less conserved N-terminal portions of each coding sequence by PCR amplification, using the oocyte expression sense primer and the Northern antisense primer (see Table 1), and subcloned into pBluescript II (Stratagene). Restriction fragments for hybridization were labeled by random priming, as described above.

Fusion protein constructs. Sequence conservation between human (hEAAT1) and salamander EAAT1 (sEAAT1) subtypes allowed antisera prepared against a human glutathione $S$-transferase (GST) fusion protein to be used in these studies. The divergent amino acid sequences of the C termini of sEAAT2A, sEAAT2B, and sEAAT5A also were expressed as GST fusion proteins to obtain subtype-selective antisera. The N-terminal boundary of the C-terminal sequences for sEAAT2A, sEAAT2B, and sEAAT5A is indicated by an arrow and the circled number 2 in Figure $1 B$. The epitope chosen for hEAAT1 is at the same alignment point. Products from standard coding sequence PCR conditions with the primer pairs given in Table 1 were subcloned into pGEX-KT for expression in DH5 $\alpha$ bacteria and protein purification. The exception to this strategy was sEAAT5B; sEAAT5B antisera were raised against the peptide sequence acetyl-SNTQRRPITKEHEVM*C-amide, where $\left(\mathrm{M}^{*}\right)$ is norleucine. (The location of this peptide is underlined in Figure $1 B$.) In addition, a truncated SEAAT5A fusion protein was subcloned into pMAL-c2 (New England BioLabs), using a second antisense PCR primer (sEAAT5A antisense HindIII; see Table 1), and the resulting maltose binding protein (MBP)/sEAAT5A fusion protein was used to affinity-purify the sEAAT5A antisera. This truncation at aspartate 551 removed the last 13 residues that contain a putative PDZ domain interaction sequence (Arriza et al., 1997).

Antibody generation and affinity purification. hEAAT1, sEAAT2A, sEAAT2B, and sEAAT5A C-terminal GST fusion proteins were used for rabbit immunizations (Hazleton Research Products, Denver, PA) and for subsequent affinity purification and control blocking experiments with the antisera. Antisera were purified on affinity columns, where GST or GST fusion proteins were coupled to Affi-Gel 15 (Bio-Rad, Richmond, CA). sEAAT5A antiserum was purified on an affinity column containing the MBP/truncated sEAAT5A fusion protein. Serum diluted $50 \%$ in $0.1 \mathrm{M}$ 4-morpholinepropanesulfonic acid (MOPS) buffer, $\mathrm{pH} 7.5$, was bound for $30 \mathrm{~min}$ at $4^{\circ} \mathrm{C}$ to a protein-coupled Affi-Gel column and then washed with $0.1 \mathrm{M}$ MOPS, $\mathrm{pH}$ 7.5. Bound antisera were eluted with $50 \mathrm{~mm}$ diethylamine, collected into $1 \mathrm{M}$ MOPS, and then concentrated with an Amicon (Beverly, MA) ultrafiltration cell. Affinity-purified antibodies were stored in $50 \%$ glycerol $/ 0.02 \%$ sodium azide at $-20^{\circ} \mathrm{C}$. sEAAT5B peptide antisera were produced and affinity-purified by Quality Control Biochemicals (Hopkinton, MA).

Western blotting. Dissected retinas were homogenized in a buffer containing 2\% SDS, $60 \mathrm{~mm}$ Tris, $\mathrm{pH}$ 6.8, $100 \mathrm{~mm}$ DTT, and 1 mm EDTA at a $1: 10 \mathrm{w} / \mathrm{v}$ ratio. After incubation for $30 \mathrm{~min}$ at $37^{\circ} \mathrm{C}$, tissues were processed four times through 20 gauge and then through 26 gauge needles and spun at $10,000 \times g$ at $4^{\circ} \mathrm{C}$. Supernatants were frozen at $-20^{\circ} \mathrm{C}$. Proteins were resolved on a $8 \%$ polyacrylamide gel under denaturing conditions and transferred to Immobilon P (Millipore, Bedford, MA). Blots were blocked with $5 \%$ nonfat powdered milk, $1 \% \mathrm{BSA}, 150 \mathrm{~mm} \mathrm{NaCl}$, and $10 \mathrm{~mm}$ Tris, $\mathrm{pH}$ 7.4. Antisera were preincubated overnight at $4^{\circ} \mathrm{C}$ either with GST or GST fusion protein or with the peptide antigen (sEAAT5B) at the following concentrations: anti-hEAAT1 at $2 \mu \mathrm{g} / \mathrm{ml}$ with GST or GST-EAAT1 at $40 \mu \mathrm{g} / \mathrm{ml}$; anti-sEAAT2A at $8 \mu \mathrm{g} / \mathrm{ml}$ with GST or GST-sEAAT2A at 56 $\mu \mathrm{g} / \mathrm{ml}$; anti-sEAAT2B at $9 \mu \mathrm{g} / \mathrm{ml}$ with GST or GST-sEAAT2B at $63 \mu \mathrm{g} / \mathrm{ml}$; anti-sEAAT5A at $20 \mu \mathrm{g} / \mathrm{ml}$ with GST or GST-sEAAT5A at $50 \mu \mathrm{g} / \mathrm{ml}$; and anti-sEAAT5B at $20 \mu \mathrm{g} / \mathrm{ml}$ with or without peptide at $20 \mu \mathrm{g} / \mathrm{ml}$. Blots were incubated for $1 \mathrm{hr}$ at room temperature with primary antisera and then washed four times for $10 \mathrm{~min}$ with $150 \mathrm{~mm} \mathrm{NaCl}, 10 \mathrm{~mm}$ Tris, $\mathrm{pH}$ 7.4, and $1 \%$ Tween-20 (TST) and then incubated for $1 \mathrm{hr}$ in TST containing a donkey anti-rabbit Ig horseradish peroxidase-linked secondary antibody (Amersham, Arlington Heights, IL) at 1:10,000 concentration. After being washed with TST, protein bands were detected by chemiluminescence (NEL-102, DuPont NEN, Boston, MA) and by exposure to film (Kodak XAR) for periods from $1 \mathrm{~min}$ to $2 \mathrm{hr}$.

Tissue preparation for immunohistochemistry. Eyes were dissected from larval tiger salamanders, and the cornea and lens were removed. For slices, the resulting eyecups were fixed in a $4 \%$ paraformaldehyde PBS solution, $\mathrm{pH} 7.4$, overnight at $4^{\circ} \mathrm{C}$. Eyecups were cryoprotected in a $30 \%$ sucrose solution for 8-12 hr and subsequently embedded in OCT containing 3\% glycerol. Frozen eyecups were sectioned at $12 \mu \mathrm{m}$ thickness with a cryostat, placed onto slides coated with Cell-Tak (Collaborative Biomedical Products, Bedford, MA), and stored desiccated at $-80^{\circ} \mathrm{C}$ for $<2$ months. Dissociated cells were prepared according to Eliasof and Jahr (1996). Briefly, isolated retinae were incubated twice in a divalent- 
free Ringer's solution containing $8 \mathrm{U} / \mathrm{ml}$ papain (Worthington Biochemical, Freehold, $\mathrm{NJ}$ ) and $1 \mathrm{mg} / \mathrm{ml}$ cysteine for $15 \mathrm{~min}$ each at $30^{\circ} \mathrm{C}$. The retinae were quenched for $10 \mathrm{~min}$ in $1 \mathrm{mg} / \mathrm{ml}$ bovine albumin, rinsed, chopped into pieces, and gently triturated with a fire-polished Pasteur pipette. The resulting cell suspension was placed on a microscope slide coated with concanavalin A. Cells were fixed with $4 \%$ paraformaldehyde and stored at $4^{\circ} \mathrm{C}$ in PBS containing $0.2 \%$ sodium azide.

Immunofluorescence. Sections were air-dried, baked for $30 \mathrm{~min}$ at $37^{\circ} \mathrm{C}$ in a vacuum oven, and post-fixed with $3.7 \%$ formaldehyde in PBS Sections were blocked and permeabilized with $5 \%$ horse serum $/ 0.1 \%$ Triton X-100 in PBS for $1 \mathrm{hr}$ at $25^{\circ} \mathrm{C}$ and then incubated with the primary antibody overnight at $4^{\circ} \mathrm{C}$. Antibody and GST fusion protein concentrations were as follows: anti-sEAAT1 at $5 \mu \mathrm{g} / \mathrm{ml}$ and GST or GST-sEAAT1 at $35 \mu \mathrm{g} / \mathrm{ml}$, anti-sEAAT2A at $12 \mu \mathrm{g} / \mathrm{ml}$ and GST or GST-sEAAT2A at $100 \mu \mathrm{g} / \mathrm{ml}$, anti-sEAAT2B at $30 \mu \mathrm{g} / \mathrm{ml}$ and GST or GST-sEAAT2B at $100 \mu \mathrm{g} / \mathrm{ml}$, anti-sEAAT5A at $20 \mu \mathrm{g} / \mathrm{ml}$ and MBP or MBP-sEAAT5A at $50 \mu \mathrm{g} / \mathrm{ml}$, and anti-sEAAT5B at $5 \mu \mathrm{g} / \mathrm{ml}$ with or without peptide at 40 $\mu \mathrm{g} / \mathrm{ml}$. After being washed with PBS, retina sections were incubated with 1:100 cyanin5 (Cy5)-conjugated donkey anti-rabbit $\mathrm{IgG}(\mathrm{H}+\mathrm{L})$ (Jackson ImmunoResearch Laboratories, West Grove, PA). Sections were washed again in PBS and coverslipped with Slow Fade (Molecular Probes, Eugene, OR). Sections were imaged with a Bio-Rad MRC-1000 krypton-argon laser scanning confocal microscope and a Nikon Diaphot 200 inverted microscope with a Nikon PlanApo $60 \times$ oil lens (numerical aperture, 1.40). Projection images are a maximum composite $z$-series of optical sections collected at $0.5 \mu \mathrm{m}$ intervals by Bio-Rad Lasersharp 1024 software. All control tissues were imaged with identical parameters to enable direct visual comparisons of staining. Differential interference contrast (DIC) images were collected for each imaged tissue.

Dissociated retina cells were incubated with $5 \%$ horse serum $/ 0.1 \%$ Triton $\mathrm{X}-100$ in PBS and then with primary antisera at $4^{\circ} \mathrm{C}$ overnight, using the concentrations given above for retinal slices. Then cells were washed with PBS and incubated with Cy5-conjugated donkey anti-rabbit $\operatorname{IgG}(\mathrm{H}+\mathrm{L})$ (Jackson ImmunoResearch Laboratories) for $1 \mathrm{hr}$ at room temperature. After being washed with PBS, cells were coverslipped with Slow Fade (Molecular Probes). Images were collected as single $0.5 \mu \mathrm{m}$ confocal optical slices, using a $60 \times$ oil lens.

Recording solutions. Normal extracellular solution (nd96) consisted of (in $\mathrm{mM}$ ): $96 \mathrm{NaCl}, 2 \mathrm{KCl}, 1.8 \mathrm{CaCl}_{2}, 1 \mathrm{MgCl}_{2}$, and $5 \mathrm{Na}_{1 / 2} \mathrm{HEPES}, \mathrm{pH}$ 7.5. Sodium dose-response curves (Table 3) were measured with various combinations of $\mathrm{NaCl}$ and $\mathrm{N}$-methyl D-glucamine (NMDG) $\mathrm{Cl}$, with a total cation concentration of $96 \mathrm{~mm}$. For the subtype sEAAT2B, the low affinity for sodium required a maximal sodium concentration of $160 \mathrm{~mm}$, and in this case $96 \mathrm{~mm} \mathrm{NaCl}$ plus $64 \mathrm{~mm}$ Na gluconate was used. For all sodium experiments, free acid HEPES was used, and the $\mathrm{pH}$ was adjusted with NMDG. Chloride-free extracellular solutions contained gluconate salts, replacing all chloride salts. Nitrate extracellular solution contained $96 \mathrm{~mm} \mathrm{NaNO}$, replacing $96 \mathrm{~mm} \mathrm{NaCl}$. Amino acids and transporter inhibitors were added directly to the appropriate extracellular solution.

Recording and analysis. Two-electrode voltage-clamp recordings were made by using two glass electrodes filled with $3 \mathrm{M} \mathrm{KCl}$; the tip resistance was between 200 and $700 \mathrm{kOhm}$. Recordings were amplified with a Gene Clamp 500 amplifier interfaced to a Digidata 1200, and data were acquired with pClamp6 software (Axon Instruments, Foster City, CA). Data were filtered at $2 \mathrm{kHz}$ and acquired at $5 \mathrm{kHz}$.

Oocytes were held at $-30 \mathrm{mV}$ (except where indicated) and stepped to a range of potentials from -140 to $+80 \mathrm{mV}$ for $100 \mathrm{msec}$. Currentvoltage relations from a single cell were measured as the difference between the steady-state currents (the current averaged over the last 20 $\mathrm{msec}$ ) in the absence and presence of substrate. The differences were taken by using the control currents both before and after the application of substrate, and the two resulting current-voltage curves were averaged together. Each experiment was performed in four to six cells, and the average current-voltage curves are shown. The error bars indicate SEM.

Dose-response curves were generated by using the same voltage protocol. The averaged steady-state currents were normalized to the response to $1 \mathrm{~mm}$ L-glutamate measured in the same cells. Then the data at each potential were fit to either a Michaelis-Menten or Hill equation, using the Levenberg-Marquardt algorithm provided by Origin (Microcal, Northhampton, MA). The dose-response curves plotted in this paper are all at a command potential of $-60 \mathrm{mV}$. The error bars indicate SEM.

Radiolabeled uptake. Radiolabeled uptake was performed under voltage clamp. Cells were held at $-60 \mathrm{mV}$, and $100 \mu \mathrm{M}\left[{ }^{3} \mathrm{H}\right]$ L-glutamate $(20$ $\mathrm{Ci} / \mathrm{mol}$ ) was added directly to the bath for $100 \mathrm{sec}$. To control for nonspe- cific binding or uptake of $\left[{ }^{3} \mathrm{H}\right]$ L-glutamate, we performed uptake under identical conditions in oocytes not possessing any of the glutamate transporter clones (labeled "uninjected" in Table 4). The cells subsequently were washed in unlabeled extracellular solution for at least $1 \mathrm{~min}$ before lysis in a $1 \%$ SDS for $>15 \mathrm{~min}$ and counted in $2 \mathrm{ml}$ of scintillation fluid. Shorter wash times did not decrease radiolabeled uptake significantly, presumably because the low extracellular potassium concentration $(2 \mathrm{mM})$ and negative membrane potential are not favorable conditions for the release of intracellular glutamate (our unpublished observations). For charge-to-flux experiments, the current was measured and the total charge integral computed. Charge was converted to moles by using Faraday's constant.

Measurement of the chloride equilibrium potential. The chloride equilibrium potential $\left(E_{\mathrm{Cl}}\right)$ was approximated as described by Wadiche et al. (1995). Briefly, current-voltage curves were measured before and after the application of the calcium ionophore 4-Br A23187 (Calbiochem, La Jolla, $\mathrm{CA})$. The influx of calcium generates a large calcium-dependent chloride current present in oocytes (Barrish, 1983), and so the reversal potential of the ionophore-induced current is a close approximation of $E_{\mathrm{Cl}}$.

\section{RESULTS}

\section{Complexity of EAAT subtype expression in the salamander retina}

The molecular complexity of glutamate transporter gene expression in the salamander retina was analyzed initially with a PCRbased strategy that used degenerate oligonucleotide primers. The primer sequences were based on sequence conservation within the mammalian EAAT gene family (see Table 1 and Fig. $1 A$ ). RT-PCR of retinal RNA resulted in the isolation of seven distinct cDNA products from a pool of several hundred clones characterized either by direct DNA sequencing or by hybridization. The PCR products SR6, SR24, and SR27 were represented most abundantly, SR30 and SR72 were somewhat less abundant, and SR29 and SR32 were the least represented in the pool of PCR products. To isolate full-length EAAT subtypes expressed in salamander retina, we constructed a cDNA library and screened it with a pool of the human subtypes EAAT1, EAAT2, and EAAT3 [the rat or rabbit homologs of which are referred to as GLAST (Storck et al., 1992), GLT-1 (Pines et al., 1992), and EAAC1 (Kanai and Hediger, 1992), respectively] at reduced stringency (see Materials and Methods). Clones corresponding to the partial products SR6, SR24, SR27, SR30, and SR72 were isolated from this screening and because of homology with human transporter subtypes

(see below) were renamed sEAAT1, sEAAT2A, sEAAT2B, sEAAT5A, and sEAAT5B, respectively. The sequences of these five clones are shown in Figure $1 B$. Further attempts to obtain full-length cDNA clones corresponding to SR29 and SR32, using the PCR products as probes, were unsuccessful, suggesting that they occur in very low abundance. The library also was screened with the human EAAT3 and EAAT4 cDNAs at reduced stringency, and no new clones were obtained. Thus, although the limited SR32 sequence is structurally most similar to EAAT3, we have no evidence that EAAT3-like expression occurs at a significant level in the salamander retina. The SR29 sequence, on the other hand, is nearly identical to SR6 in amino acid sequence and differs in only $\sim 5 \%$ of its nucleotide sequences. Because the salamander genome is known to be polyploid, these may represent allelic differences. Finally, an EAAT4 homolog was not encountered in either the PCR products or in the library screening, suggesting that an EAAT4-like subtype is not expressed in the salamander retina.

Structural homologies of the salamander genes with the human EAATs were used to assign subtype relationships. The library cDNA containing the sEAAT1 sequence was $87 \%$ identical with human EAAT1 but had only $44 \%$ identity with the next most 


\begin{tabular}{|c|c|c|c|c|}
\hline Table 1. PCR Primer sec & \multirow[t]{2}{*}{ Enzyme } & \multicolumn{3}{|c|}{$(\mathrm{N})_{4}$ site homologous sequence } \\
\hline \multicolumn{4}{|l|}{ Degenerate PCR } & \\
\hline ATINMDG & & & & GCNACNATHAAYATGGAYGG \\
\hline AA (i/v) FIAQ & BamH1 & CGCG & GGATCC & GCNGCNRTNTTYATHGCNCA \\
\hline AVDW (f/l) LD & $X b a 1$ & CGCG & TCTAGA & TCNARNARCCARTCNACNGCNA \\
\hline \multicolumn{5}{|l|}{ Oocyte expression } \\
\hline sEAAT1 sense & XhoI & CGCG & CTCGAG & GCAATGACCAAAAGTAAC \\
\hline sEAAT1 antisense & $X b a 1$ & CGCG & TCTAGA & TCACATCTTGGTCTCGC \\
\hline sEAAT2A sense & $K p n \mathrm{I}$ & CGCG & GGTACC & ACCATGACTTCCACAGAG \\
\hline sEAAT2A antisense & $X b a 1$ & CGCG & TCTAGA & CTACAGGTTTTTCGTTTC \\
\hline sEAAT2B sense & KpnI & CGCG & GGTACC & GACCTGACAAACAACGTG \\
\hline sEAAT2B antisense & Xba 1 & CGCG & TCTAGA & CTAGTCCTCCATtTTCTT \\
\hline sEAAT5A sense & KpnI & CGCG & GGTACC & GCCATGGCGGTGACTGTG \\
\hline sEAAT5A antisense & $X b a 1$ & CGCG & TCTAGA & CTACACGTTTGTTTCAAC \\
\hline sEAAT5B sense & KpnI & CGCG & GGTACC & ATCATGTGGGAGCGCATC \\
\hline sEAAT5B antisense & $X b a 1$ & CGCG & TCTAGA & GTACTTCGGTTAAACCTG \\
\hline \multicolumn{5}{|l|}{ Northern probe } \\
\hline sEAAT1 antisense & $X b a 1$ & CGCG & TCTAGA & CACAGGGATCATCTCCTC \\
\hline sEAAT2A antisense & $X b a 1$ & CGCG & TCTAGA & CATCCTTGAACTCAAGAC \\
\hline sEAAT2B antisense & $X b a 1$ & CGCG & TCTAGA & CAGTtTCTTCTGTGTCAC \\
\hline sEAAT5A antisense & Xba 1 & CGCG & TCTAGA & GGCTCAGATTTGTAGATC \\
\hline sEAAT5B antisense & $X b a 1$ & CGCG & TCTAGA & СССАAАACATTCATTTCTG \\
\hline \multicolumn{5}{|l|}{ C-terminal fusion } \\
\hline hEAAT1 sense & Bam $\mathrm{H} 1$ & GCGC & GGATCC & CGACATGAACTGAAGAAC \\
\hline hEAAT1 antisense & EcoR1 & GCGC & GAATTC & CTACATCTTGGTTTCACTG \\
\hline sEAAT2A sense & Bam $\mathrm{H} 1$ & CGCG & GGATCC & CTCTCCAGAGCCGAATTG \\
\hline sEAAT2A antisense & EcoR1 & CGCG & GAATTC & TACAGGTTTTTCGTTTC \\
\hline sEAAT2B sense & Bam $\mathrm{H} 1$ & CGCG & GGATCC & СTTTCAAAGGCTGAACTTG \\
\hline sEAAT2B antisense & EcoR1 & CGCG & GAATTC & TAGTCCTCCAтTTTCTTTT \\
\hline sEAAT5A sense & Bam $\mathrm{H} 1$ & CGCG & GGATCC & ATCTGCAGAAAGGATTTTG \\
\hline sEAAT5A antisense & EcoR1 & CGCG & GAATTC & TACACGTTTGTTTCAACT \\
\hline sEAAT5A antisense & HindIII & CGCG & AAGCTT & AGTCCTTGTCGTTGGATAC \\
\hline
\end{tabular}

Nucleotide sequences of PCR primers used to isolate regions of cDNA for various applications. Locations of primers other than $\mathrm{N}$ and $\mathrm{C}$ termini are indicated in Figure 1 (see legend). Enzyme and Site refer to restriction endonuclease sites included in the primer sequences. $(\mathrm{N})_{4}$ is a four-nucleotide sequence that facilitates restriction. Nucleotides are indicated using standard IUPAC code symbols.

closely related sequence (EAAT4). Similarly, sEAAT2A was derived from a gene product with $84 \%$ identity to human EAAT2 and is likely to be the salamander homolog. However, a second gene was identified with $62 \%$ identity with EAAT2 and a $61 \%$ identity with sEAAT2A, but only $36 \%$ with the next closest subtype, EAAT1. Based on this structural homology and the sensitivity to kainate (see below), this clone is considered to be part of the EAAT2 subfamily and has been termed sEAAT2B. Finally, the sEAAT5A and sEAAT5B coding sequences represent two distinct homologs of the new glutamate transporter subtype EAAT5 (Arriza et al., 1997). sEAAT5A and sEAAT5B are $58 \%$ identical with each other, sEAAT5A has $77 \%$ amino acid sequence identity with EAAT5, and sEAAT5B has 58\% sequence identity with EAAT5. Fewer N-linked glycosylation sites are observed in the sEAAT5 subclass; only one glycosylation site occurs in sEAAT5A and none is present in sEAAT5B (Fig. 1B). We have been unable to observe the function of sEAAT5B in the oocyte expression system (see below) despite immunological evidence of expression, an observation that may be related to the reduced stability and inefficient surface targeting of nonglycosylated carriers, as has been observed for other transporters (Melikian et al., 1994; Conradt et al., 1995; Nguyen and Amara, 1996). Indeed, immunostaining indicates the presence of crude mem- brane preparation, but it does not indicate whether it is present in surface or intracellular membrane. The assignment of sEAAT5B as a glutamate transporter, therefore, is based on structure rather than function.

\section{Subtype-selective probes for gene expression}

Evidence for expression of each sEAAT subtype mRNA and protein was obtained from Northern blot and Western blot analyses (Fig. 2). Northern blotting of salamander retina RNA (Fig. $2 A)$ with subtype-specific cDNA probes detected the following discrete mRNA species: sEAAT1, 4.1 kilobases (kb); sEAAT2A, $>12 \mathrm{~kb}$; sEAAT2B, $7.5 \mathrm{~kb}$ and $4.2 \mathrm{~kb}$; sEAAT5A, $2.5 \mathrm{~kb}$; and sEAAT5B, $3.0 \mathrm{~kb}$. As expected, the size of the mRNA is at least as large as the coding sequence for all five transporter subtypes. The presence of two bands for sEAAT2B could represent the use of alternative polyadenylation sites, alternative transcriptional start sites, or alternative exons, or they could be the products of two highly homologous genes. Similar results have been reported with other members of the glutamate transporter gene family, such as the neuronal glutamate transporter EAAC1 (rabbit EAAT3; Kanai and Hediger, 1992) and the neutral amino acid transporter ASCT1 (Arriza et al., 1993). Band intensity and exposure times generally support the relative abundance indi- 


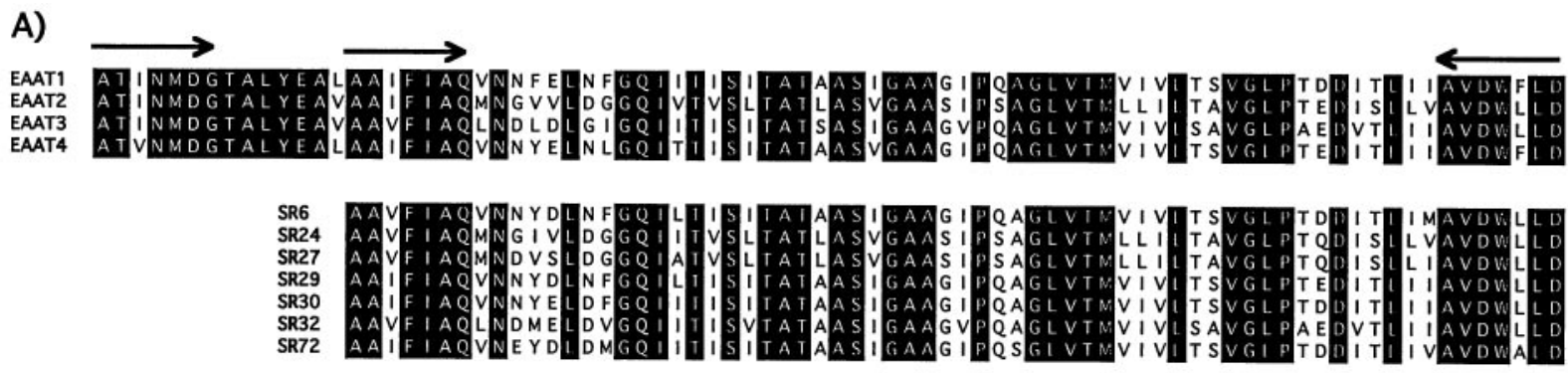

B)

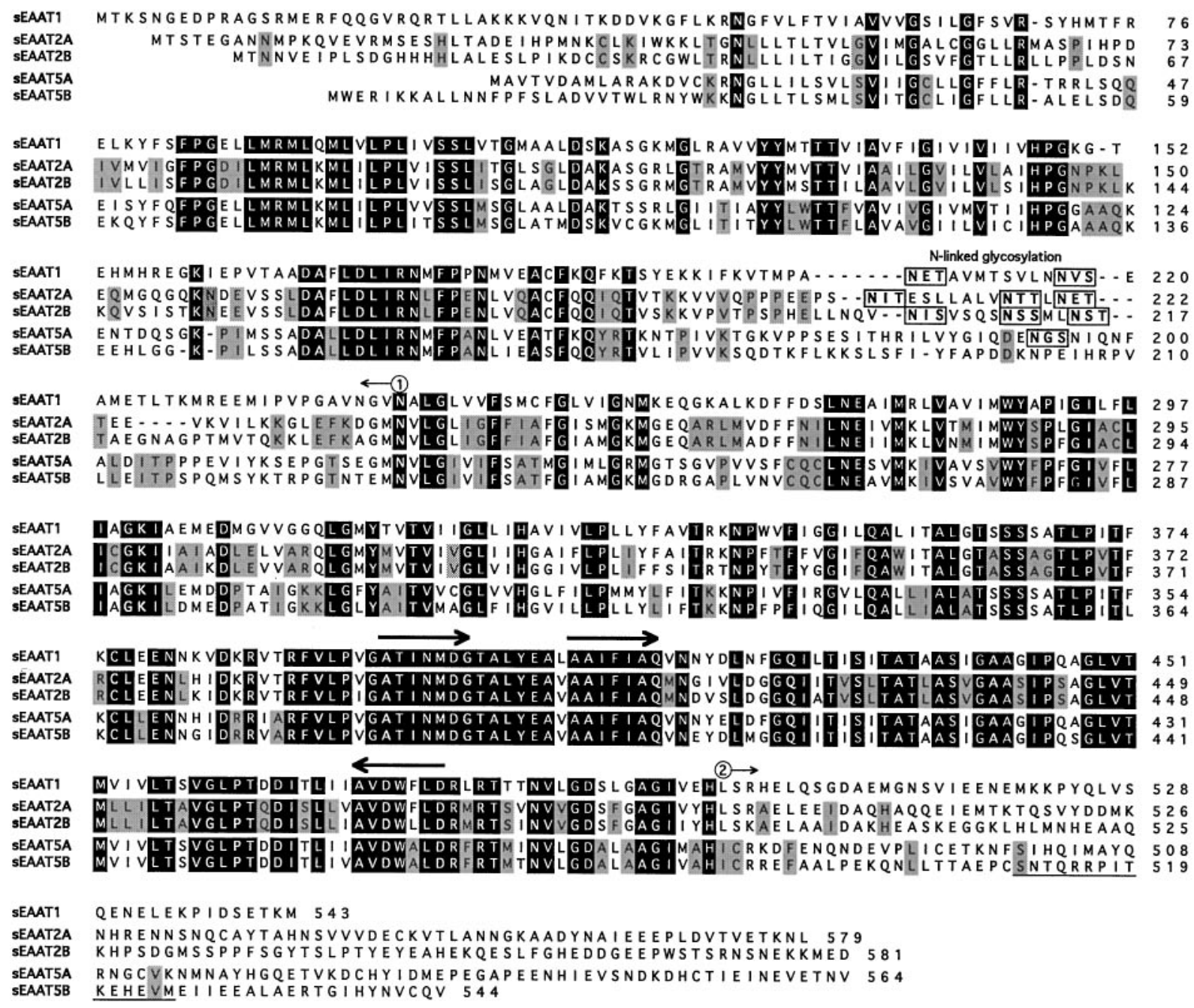

Figure 1. Glutamate transporter genes expressed in salamander retina. $A$, Seven distinct partial salamander cDNAs were isolated by PCR, using degenerate oligonucleotide primers. The sequence conservation used for primer design (indicated by arrows; see Table 1 for primer sequences) is illustrated at top in an alignment of four human amino acid sequences, EAAT1 through EAAT4. The predicted sequences of salamander retina PCR products (designated SR6, SR24, etc.) are shown below. B, Alignment of five complete amino acid coding sequences isolated from a salamander retina cDNA library. These sequences are designated salamander EAATs $(s E A A T s)$ on the basis of structural and functional correlations with the human EAATs (see Results). These sEAAT sequences are related to the partial sequences shown in $A$ as follows: sEAAT1, SR6; sEAAT2A, SR24; sEAAT2B, SR27; sEAAT5A, SR30; and sEAAT5B, SR72. Amino acid sequence numbering is indicated to the right. Sequence length for each gene product is sEAAT1, 543 amino acids (aa); sEAAT2A, 579 aa; sEAAT2B, 581 aa; sEAAT5A, 564 aa; and sEAAT5B, 544 aa. Residues identical in all subtypes are indicated by white lettering on black, whereas residues seen only in a particular subclass (e.g., sEAAT2A and B, sEAAT5A and B) are shaded. Potential $\mathrm{N}$-linked glycosylation sites N-X-(S/T) are boxed. 1 indicates the $3^{\prime}$ border of region used for Northern blot cDNA probe (see Materials and Methods and Northern probe antisense oligonucleotide in Table 1). 2 indicates the N-terminal boundary of the C-terminal sequences fused to GST for antisera production (see Materials and Methods and C-term fusion sense oligonucleotide in Table 1). Residues in sEAAT5B contained in the antigenic peptide are underlined. The nucleotide sequences of sEAAT1, sEAAT2A, sEAAT2B, sEAAT5A, and sEAAT5B may be obtained from the GenBank database under accession numbers AF018256, AF018257, AF018258, AF018259, and AF018260, respectively. 

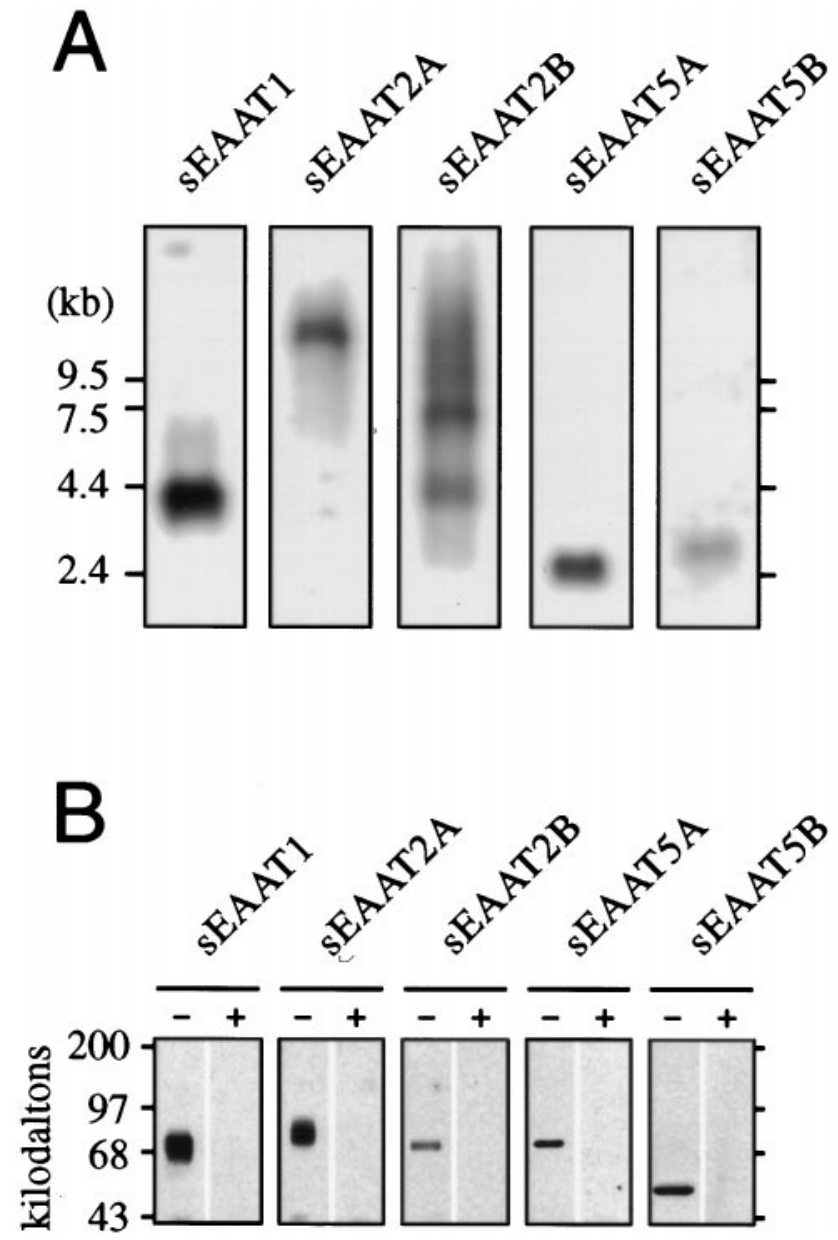

Figure 2. Northern and Western blots in salamander retina. $A$, sEAAT subtype mRNA expression in retina. Shown are Northern blots of total RNA $(20 \mu \mathrm{g})$ isolated from salamander retina hybridized with sEAAT subtype cDNA probes. Size markers in kilobases are indicated (left). $B$, Western blotting of protein from salamander retina with subtype-specific antisera. Duplicate blots were probed with subtype antisera in the absence $(-)$ or presence $(+)$ of the specific competing antigen; antigens were sEAAT C termini fused with GST or C-terminal-derived peptide ( $s E A A T 5 B$ only). Position of protein size markers in kilodaltons is shown (at left). Predicted (nonglycosylated) molecular weight for each gene product is sEAAT1, $59.4 \mathrm{kDa}$; sEAAT2A, $63.0 \mathrm{kDa}$; sEAAT2B, $62.8 \mathrm{kDa}$; sEAAT5A, $61.5 \mathrm{kDa}$; and sEAAT5B, $59.6 \mathrm{kDa}$.

cated by PCR analyses, with the approximate order as follows: sEAAT $1>\operatorname{sEAAT} 2 \mathrm{~A} \approx \operatorname{sEAAT} 2 \mathrm{~B} \approx \operatorname{sEAAT} 5 \mathrm{~A}>$ sEAAT5B.

To determine the presence of transporter protein in the retina, we generated affinity-purified subtype-specific antisera from the $\mathrm{C}$-terminal sequences indicated in Figure $1 B$. There are several reasons why the five different antibodies are unlikely to crossreact. First, the epitopes were chosen from the highly divergent region of the $\mathrm{C}$ terminus. Second, the different antibodies exhibit distinct staining patterns, as shown in Figure 4. The only transporter antibodies that appear to produce similar staining are sEAAT5A and sEAAT5B. However, the sEAAT5A antibody is directed to a GST fusion protein, whereas the sEAAT5B antibody is directed to a peptide, and so it is extremely unlikely that any cross-reactivity exists here. Finally, we did not see crossreactivity in oocytes injected with the different transporters (data not shown).

Protein representing each transporter subtype was demon- strated in salamander retina extracts by immunoblotting. Each antiserum recognizes a single prominent band in RNA-injected oocytes. In retina extracts, single prominent bands with molecular weights similar to those seen in oocytes were detected (Fig. 2B). These bands were absent in parallel blots in which the antisera were preincubated with excess antigen (compare minus and plus competing antigen lanes in Fig. 2B). Each antiserum recognized a discretely sized product in retinal homogenates, further supporting the subtype-selective nature of the antisera. There is evidence of transporter glycosylation for each subtype except sEAAT5B, which lacks a consensus N-linked glycosylation site. The sEAAT1 and sEAAT2A products appear particularly diffuse, indicating possible heterogeneous glycosylation. The apparent molecular weight of sEAAT5B is considerably less than the weights of the other subtypes, consistent with its lower predicted molecular weight and the absence of glycosylation. These analyses support the specificity of these antisera subsequently used for immunocytochemistry.

\section{Localization of sEAAT immunoreactivity}

Because salamander Müller cells are known to possess glutamate transporters (Brew and Attwell, 1987; Schwartz and Tachibana, 1990), we tested sEAAT immunoreactivity on dissociated Müller cells, using CY5-labeled immunofluorescence (Fig. 3). Cells were incubated in one of five different antisera and viewed with a confocal microscope. Müller cells showed positive immunoreactivity for all but sEAAT2B. For the other four antisera, every dissociated glial cell found was immunopositive ( $n \geq 4$ for each), suggesting that all Müller cells possess four different glutamate transporters rather than there being four distinct subtypes of Müller cells. In the presence of a competing antigen, no immunoreactivity was seen for any of the five antisera (Fig. 3; data not shown). Note that intracellular staining is present for sEAAT2A, sEAAT5A, and sEAAT5B. Such intracellular localization may indicate a less efficient surface targeting of these proteins, or it may indicate the localization of transporters in intracellular membranes. Whether these transporter proteins could function in such locations is unclear.

\section{sEAAT1}

In vivo localization of the five cloned salamander glutamate transporters was determined also (Fig. 4). sEAAT1 is present throughout the salamander retina. Immunofluorescence staining of sEAAT1 revealed the brightest staining surrounding photoreceptor cell bodies in the outer nuclear layer (ONL). In addition, membrane staining is present surrounding cell bodies in the inner nuclear layer (INL), processes in the inner plexiform layer (IPL), and Müller cell endfeet surrounding ganglion cell bodies in the ganglion cell layer (GCL).

This staining pattern can be explained in large part by the localization of sEAAT1 in Müller cells. Antibodies raised against glial fibrillary acid protein, a specific marker for Müller cells in the salamander retina, showed a very similar staining pattern (Liepe et al., 1994). In that study, glial cell processes were found in the outer plexiform layer (OPL) and IPL and surrounding cell bodies in the ONL, INL, and GCL. Similar results were obtained with antibodies for GLAST (rat EAAT1) and glutamine synthetase in the rat retina (Derouiche and Rauen, 1995; Lehre et al., 1997).

\section{$S E A A T 2 A$}

sEAAT2A is also present throughout the salamander retina. sEAAT2A staining is brightest in the ONL, OPL, and IPL (Fig. 


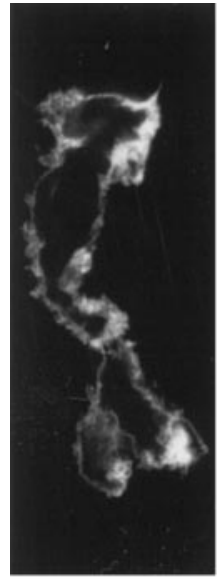

SEAAT1

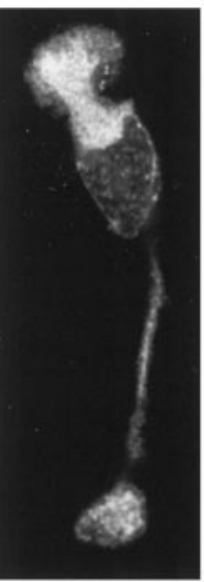

SEAAT5A

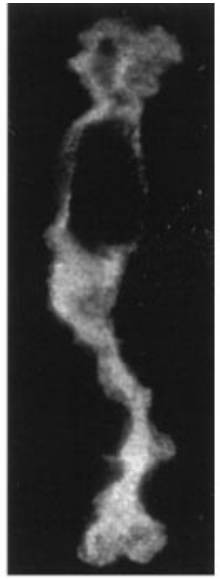

SEAAT2A

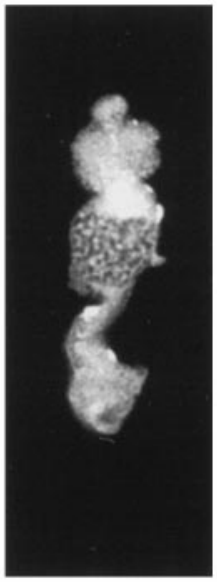

SEAAT5B

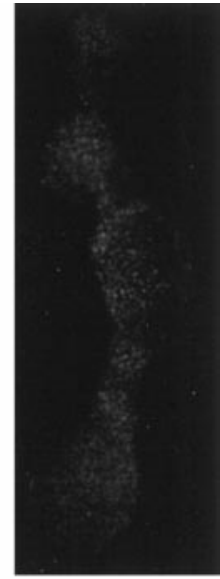

SEAAT2B

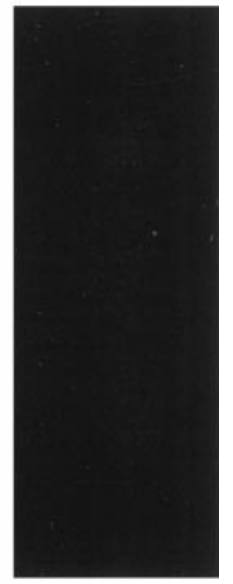

control
Figure 3. Immunofluorescence in isolate Müller cells, using subtypespecific antisera. Immunolabeling is present for sEAAT1, sEAAT2A sEAAT5A, and sEAAT5B. The image labeled control is hEAAT1 antisera in the presence of excess GST-EAAT1 fusion protein.

4). ONL staining may represent glial immunoreactivity, but sEAAT2A also may be in photoreceptors. Immunostaining of cone photoreceptors also has been observed with antibodies to purified GLT-1 (rat EAAT2) protein (Rauen and Kanner, 1994), but not with an antibody directed toward a portion of the $\mathrm{C}$ terminus (Rauen et al., 1996). Clear staining can be seen surrounding bipolar and amacrine cells in the INL, and in some cases processes emanating from these cells can be seen coursing their way through the INL toward the IPL. IPL staining is striated, being brightest in the middle. Although Müller cells stain for SEAAT2A and their processes are present in the INL and IPL, the more intense presence of sEAAT2A in the IPL and in amacrine and bipolar cell processes suggests that some of the IPL staining is also neuronal. Consistent with this, GLT-1 staining has been found in some rat depolarizing bipolar cells (Rauen and Kanner, 1994; Euler and Wässle, 1995) and amacrine cells (Rauen et al., 1996) and in some hyperpolarizing bipolar cells of the macaque monkey (Grünert et al., 1994; Rauen and Kanner, 1994). Staining of bipolar dendrites could explain some of the immunoreactivity in the OPL as well.

\section{$s E A A T 2 B$}

sEAAT2B immunoreactivity (Fig. 4) is most intense in the OPL, surrounding cell bodies in the outer half of the INL, in axons coursing from these cell bodies to the IPL, and in globular-like processes in the outer half of the IPL (Fig. 3). This staining pattern suggests that sEAAT2B is localized in OFF or hyperpolarizing bipolar cells. Hyperpolarizing bipolar cell staining by GLT-1 has been described previously in macaque retina (Grünert et al., 1994; Rauen and Kanner, 1994). Like GLT-1 staining in retinal bipolar cells of both rat and macaque monkey (Grünert et al., 1994; Rauen and Kanner, 1994; Euler and Wässle, 1995; Rauen et al., 1996), sEAAT2B appears to be both pre- and postsynaptic. Horizontal cell processes in the OPL also may be stained.

\section{sEAAT5A and $S E A A T 5 B$}

sEAAT5A and sEAAT5B have very similar staining patterns (Fig. 4), although sEAAT5A antiserum is directed against a fusion protein and sEAAT5B antiserum is directed against an unrelated peptide. Both show strong labeling in the OPL and in Müller cells. The bright staining in the OPL appears to be associated with photoreceptor terminals. In addition, faint staining can be seen in the neurons of the outer and inner nuclear layer as well as the ganglion cell layer. This is particularly clear for sEAAT5B. Thus, sEAAT5A and sEAAT5B appear to be present in both neurons and glia. Similar findings indicating widespread expression of sEAAT5A and sEAAT5B were found via the ABCDAB technique of immunocytochemistry (data not shown).

\section{Electrophysiological measurements}

All glutamate transporters cloned to date are electrogenic, and application of glutamate into the cell results in an electrical current that can be measured by electrophysiological techniques. This current consists of an inwardly rectifying transport current as well as an apparently uncoupled chloride current that varies in relative magnitude. This results in a total glutamate-elicited current with a reversal potential that depends on the relative proportion of conductance to transport (Wadiche et al., 1995).

After injection of cRNA transcribed from cDNA into Xenopus oocytes, we recorded glutamate-induced currents by using twoelectrode voltage clamp. Cells were held at $-30 \mathrm{mV}$, and the membrane potential was altered in a step-wise manner from -140 to $+80 \mathrm{mV}$ in the presence and absence of glutamate. The measured steady-state difference currents as a function of command potential elicited by application of various concentrations of L-glutamate are shown for the sEAAT1, sEAAT2A, sEAAT2B, and sEAAT5A subtypes in Figure 5. L-Glutamate elicits a concentration-dependent inwardly rectifying current for all four subtypes shown. No current was detected for oocytes injected with sEAAT5B and, as described above, may indicate a lack of targeting of sEAAT5B to the surface membrane. Therefore, we were not able to characterize the sEAAT5B clone further.

The glutamate-elicited current reversed direction in all cells expressing sEAAT1, sEAAT2A, and sEAAT5A. This can be seen more clearly in Figure 6, where a smaller voltage range is plotted (open squares). The average reversal potential for the cells from Figure 5 was $+49.3 \pm 5.2,+33.2 \pm 5.6$, and $-3.6 \pm 3.6 \mathrm{mV}$ for sEAAT1, sEAAT2A, and sEAAT5A, respectively $(n=6)$. The reversal potential was not significantly dependent on the concentration of L-glutamate, similar to previously reported studies on human transporter clones (Wadiche et al., 1995; Arriza et al., 


\section{CY5}

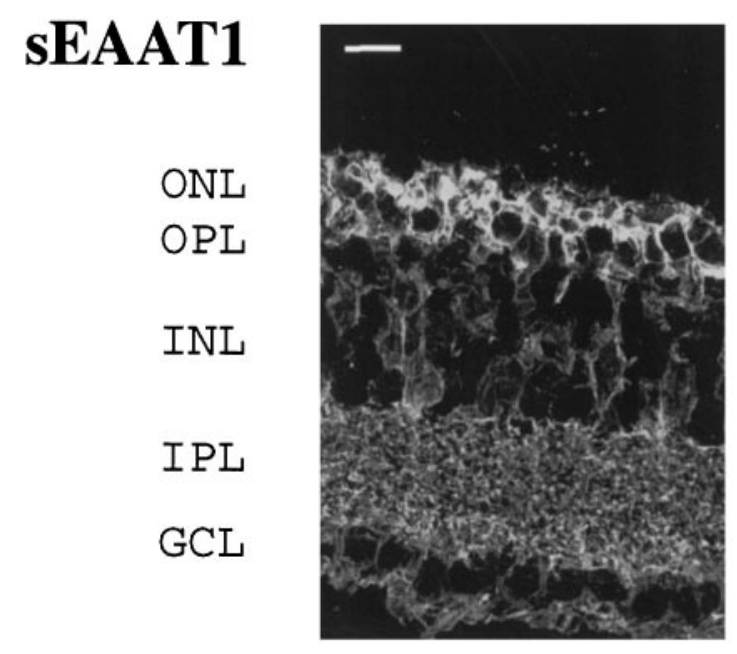

\section{sEAAT2A}

ONL

OPL

INL

IPL

GCL

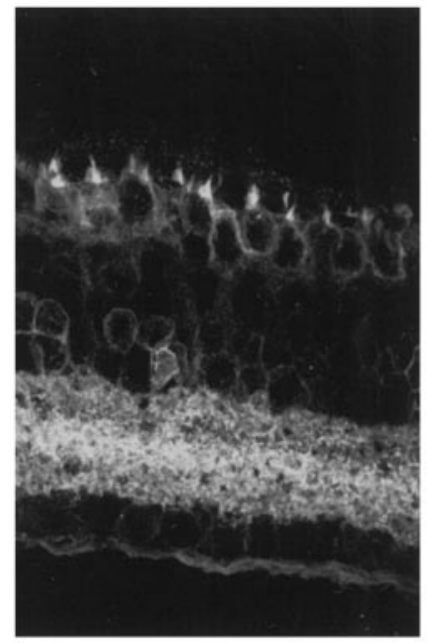

\section{SEAAT2B}

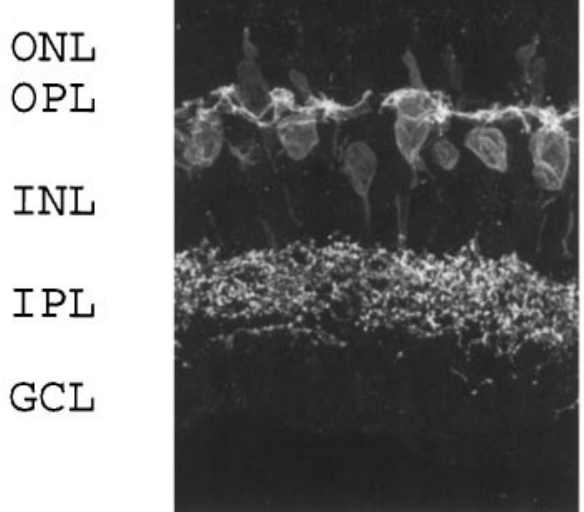

DIC
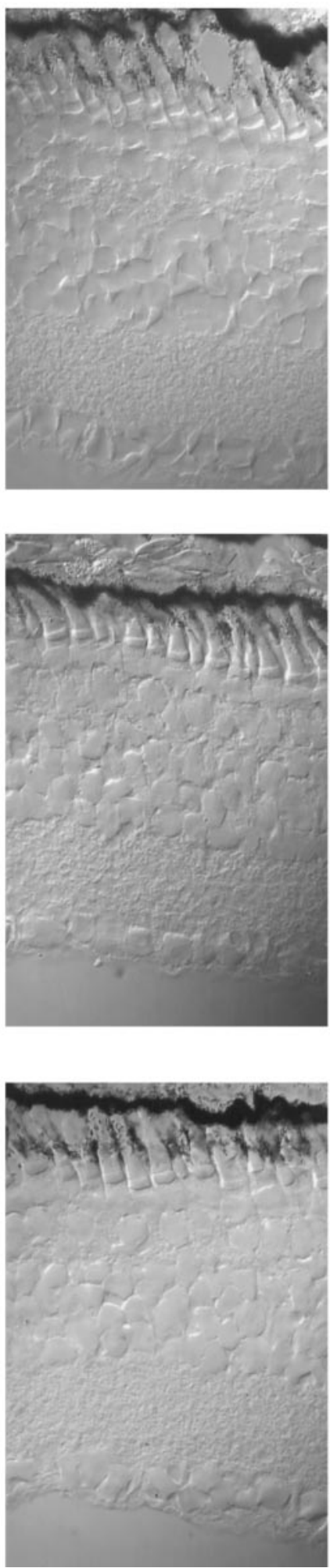

CON
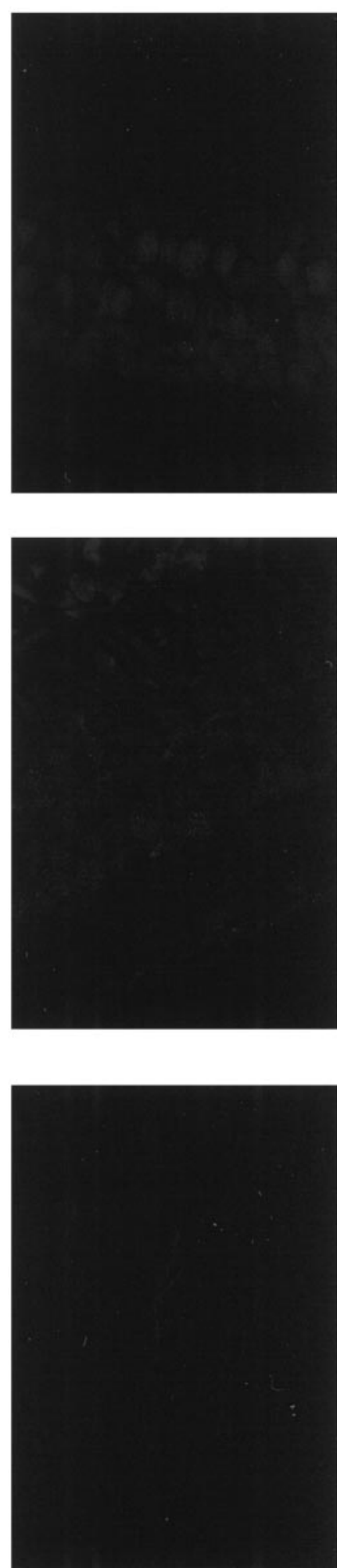

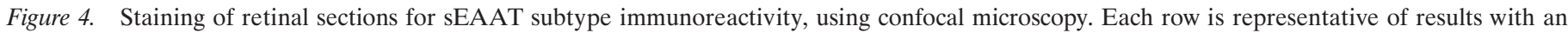
affinity-purified antisera for the indicated subtype. Column headings: CY5, cyanin5-conjugated secondary antibody; DIC, differential interference contrast image; $C O N$, antigen-competed immunostaining visualized under identical conditions. Retinal structures: $O N L$, outer nuclear layer; $O P L$, outer plexiform layer; $I N L$, inner nuclear layer; $I P L$, inner plexiform layer; $G C L$, ganglion cell layer. Scale bar (top left corner of the top left panel), $20 \mu \mathrm{m}$. 


\section{CY5}

SEAAT5A

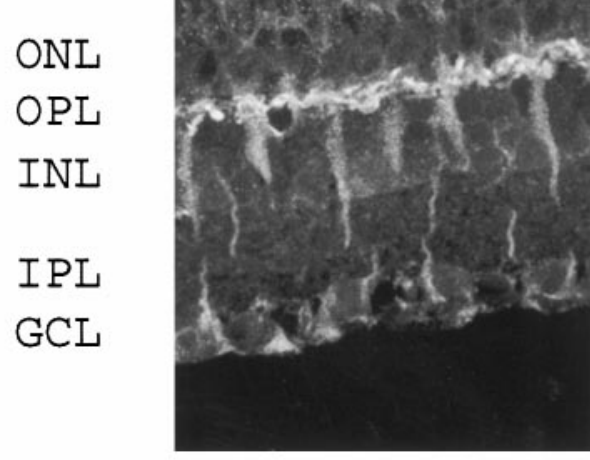

\section{SEAAT5B}

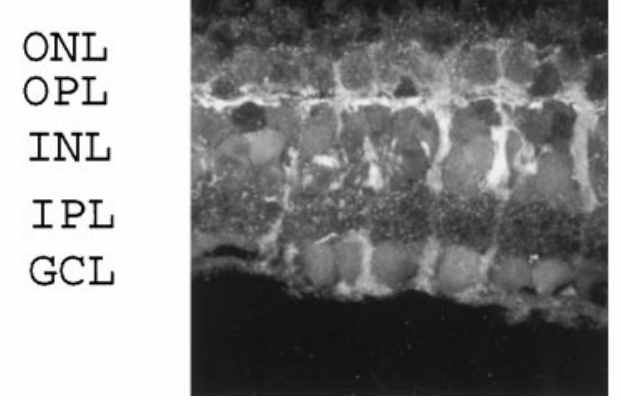

DIC
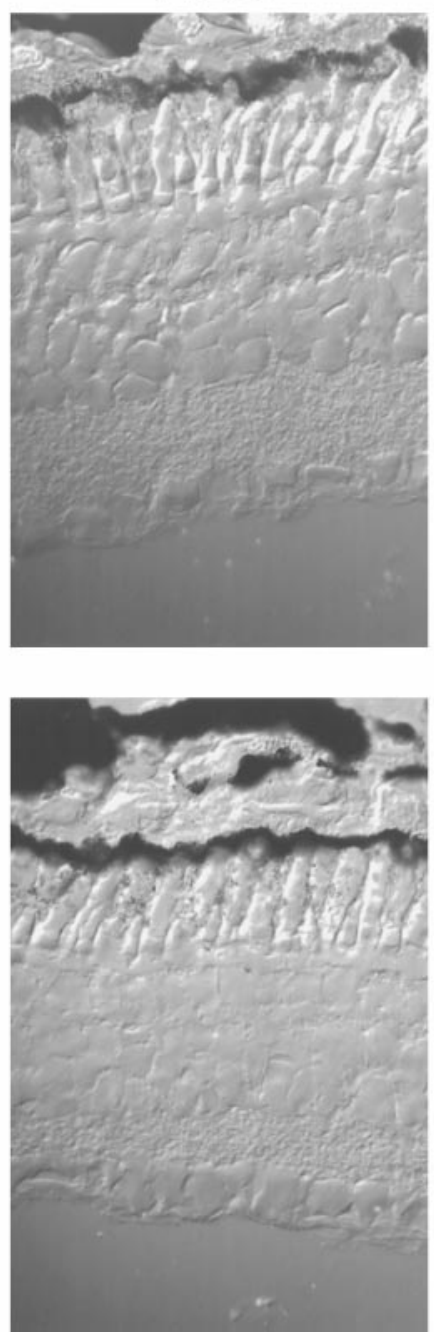

CON

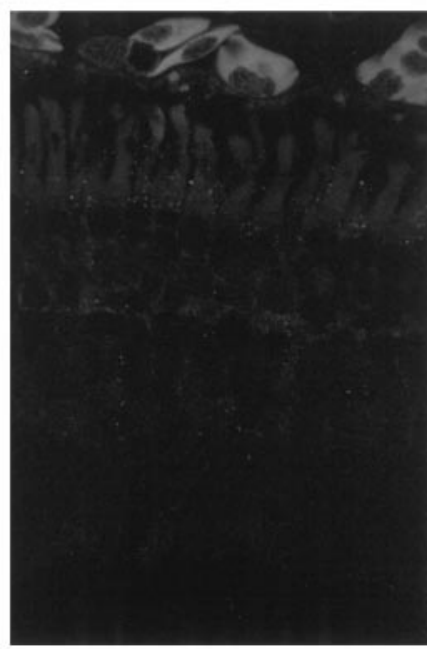

Figure 4 continued.

1997). Glutamate-elicited currents in cells expressing sEAAT2B did not reverse at potentials as positive as $+80 \mathrm{mV}$.

In addition to L-glutamate, both stereoisomers of the closely related amino acid aspartate act as good substrates for the glutamate transporters, whereas D-glutamate is transported poorly if at all. Similar experiments to those described in Figure 5 were performed by using L-aspartate, D-aspartate, and D-glutamate. The results of fitting these data to Michaelis-Menten equations are shown in Table 2. sEAAT1 has an $\mathrm{EC}_{50}$ for both forms of aspartate that is similar to the $\mathrm{EC}_{50}$ for L-glutamate, but the maximal current $\left(I_{\max }\right)$ is significantly less. sEAAT2A has a similar $I_{\max }$ and $\mathrm{EC}_{50}$ for L-glutamate and both forms of aspartate. sEAAT2B has a relatively low $\mathrm{EC}_{50}$ for both forms of aspartate, in contrast with the relatively high $\mathrm{EC}_{50}$ for L-glutamate. sEAAT5A also appears to prefer aspartate over L-glutamate. Like EAAT4, the $\mathrm{EC}_{50}$ for both forms of aspartate is an order of magnitude lower than that for L-glutamate (Fairman et al., 1995).

Three commonly used inhibitors of glutamate transport are DL-threo- $\beta$-hydroxyaspartate (THA), dihydrokainate, and kainate. THA is a competitive inhibitor that functions as a substrate with relatively high affinity (Barbour et al., 1991). We find that
THA generates a measurable inward current that is smaller than that generated by L-glutamate for all four subtypes (Table 2). It is expected that THA would be most effective at blocking uptake into SEAAT2B and SEAAT5A, where the apparent affinities for THA are nearly an order of magnitude greater than those for L-glutamate.

Kainate (and the closely related dihydrokainate), on the other hand, acts as a nontransported competitive inhibitor that is effective in the micromolar range only for the EAAT2 subtype (Arriza et al., 1994). Consistent with these findings, we found that kainate and dihydrokainate, at concentrations as high as $1 \mathrm{~mm}$, had no significant effect on currents elicited by $100 \mu \mathrm{M}$ L-glutamate in either sEAAT1 or sEAAT5A $(p>0.1$ for all conditions, using a paired two-tailed $t$ test). Specifically, at $-60 \mathrm{mV}$ in the presence of $1 \mathrm{~mm}$ dihydrokainate, $100 \mu \mathrm{M}$ L-glutamate elicited a current that was $105 \pm 12 \%$ of control in sEAAT1 and $137 \pm 39 \%$ of control in sEAAT5A. In the presence of $1 \mathrm{~mm}$ kainate, $100 \mu \mathrm{M}$ L-glutamate elicited a current that was $89 \pm 12 \%$ of control in sEAAT 1 and $98 \pm 12 \%$ of control in sEAAT5A. In contrast, both kainate and dihydrokainate inhibited sEAAT2A and sEAAT2B, the two homologs of EAAT2, in a purely competitive manner; neither kainate nor dihydrokainate elicited a current, and both 
SEAAT1

SEAAT2A

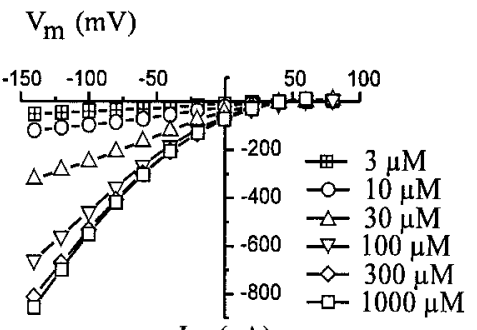

$\mathrm{I}_{\mathrm{SS}}(\mathrm{nA})$

SEAAT2B

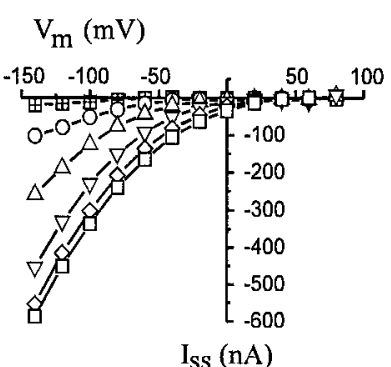

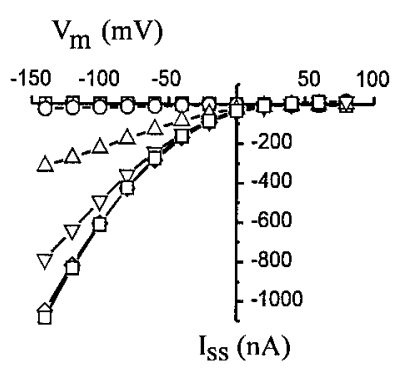

SEAAT5A

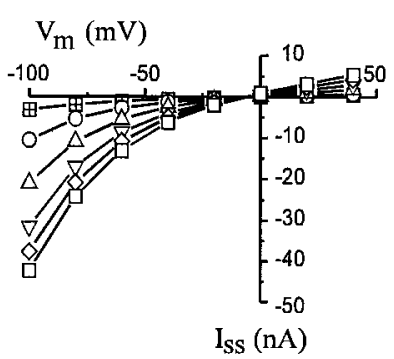

Figure 5. Current-voltage curves as a function of L-glutamate concentration. Shown are steady-state currents $\left(I_{\mathrm{ss}}\right)$ elicited in response to various concentrations of L-glutamate at various membrane potentials $\left(V_{\mathrm{m}}\right)$. Concentrations are indicated in the key (between $s E A A T 1$ and $s E A A T 2 A)$. Data from five cells have been averaged. For clarity, error bars have been excluded from this figure.

compounds shifted the dose-response curves for L-glutamate toward higher concentrations of substrate without any significant effect on the $I_{\max }$ for L-glutamate. The apparent affinity for kainate was determined by the use of Schild analysis, and the results are included in Table 2. Concentrations higher than $1 \mathrm{~mm}$ kainate were not used, so the estimates of the apparent affinity of sEAAT1 and sEAAT5A for kainate are not determined. The apparent affinities for dihydrokainate of sEAAT2A and sEAAT2B were approximated by measuring the degree of doseresponse curve shift for $1 \mathrm{~mm}$ dihydrokainate, and these data also are presented in Table 2.

\section{Ionic dependence of transport}

The transport of L-glutamate against its electrochemical gradient is driven in part by the thermodynamically coupled cotransport of three (Zerangue and Kavanaugh, 1996) sodium ions down their electrochemical gradient. Thus, removal of sodium from the extracellular medium eliminates glutamate transport. Replacing extracellular sodium with the larger cation NMDG eliminated both the inward and outward currents elicited by L-glutamate in all four subtypes (data not shown). These currents increased in magnitude as the extracellular sodium concentration was increased. The steady-state currents elicited by $100 \mu \mathrm{M}$ L-glutamate as a function of sodium concentration were fit by using the Hill equation with no fixed parameters; the sodium affinity $\left(\mathrm{Na}^{+}\right.$ $\mathrm{EC}_{50}$ ) and Hill coefficient $(n)$ are shown in Table 3. The Hill coefficient provides a lower limit of the number of sodium ions required for transport of glutamate, although it does not indicate the number of sodium ions actually transported. The Hill coefficient was $\sim 2$ for sEAAT1, sEAAT2A, and sEAAT2B, and 3 for

SEAAT1

SEAAT2A
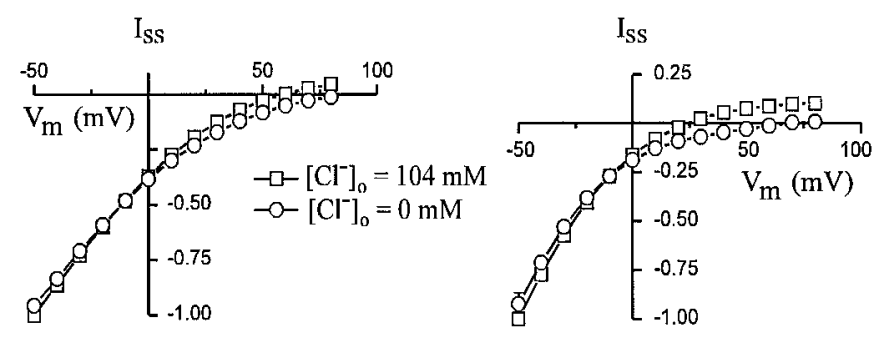

SEAAT2B

SEAAT5A
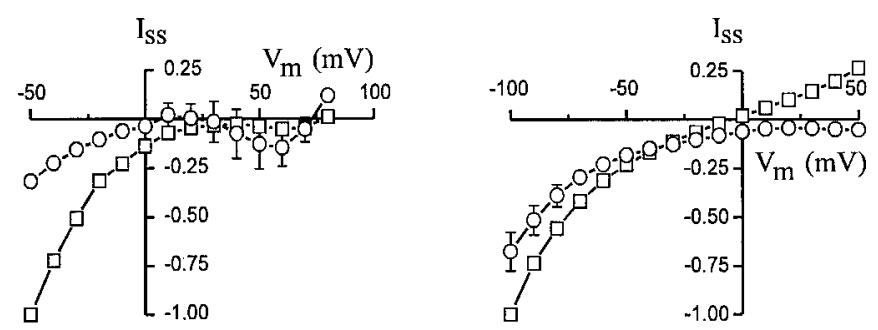

Figure 6. Current-voltage curves in chloride and chloride-free extracellular buffer. Shown are normalized steady-state currents $\left(I_{\mathrm{ss}}\right)$ elicited in response to $100 \mu \mathrm{M}$ L-glutamate at various membrane potentials $\left(V_{\mathrm{m}}\right)$ when external chloride concentration is $104 \mathrm{~mm}$ (open squares) and when external chloride is completely replaced with the impermeant anion gluconate (open circles). Data from each cell were normalized to the response to $100 \mu \mathrm{M} \mathrm{L}$-glutamate at $-50 \mathrm{mV}$ in the presence of chloride to better measure the effects of extracellular chloride on the voltage dependence of the glutamate-elicited current. Data under both conditions are from the same five cells. Error bars indicate SEM; error bars smaller than the symbols are not drawn.

sEAAT5A. The large error in measuring the Hill coefficient for sEAAT5A is attributable to the small currents elicited by glutamate for this transporter subtype.

Cones have been shown to possess a glutamate-elicited chloride conductance (Sarantis et al., 1988) that later was shown to exhibit many of the properties associated with a glutamate transporter (Picaud et al., 1995a). A similar chloride conductance associated with glutamate transport has been shown in bipolar cells, rods, and glial cells (Grant and Dowling, 1995; Billups et al., 1996; Eliasof and Jahr, 1996; Grant and Werblin, 1996). Recently, it has been demonstrated that each of the five different glutamate transporter subtypes has a detectable thermodynamically uncoupled chloride conductance (Fairman et al., 1995; Wadiche et al., 1995; Arriza et al., 1997). At sufficiently positive potentials, L-glutamate elicits an outward current caused by the influx of chloride through this conductance. This outward current can be seen more clearly by examining a more restricted voltage range, as shown in Figure 6 (open squares). Replacing extracellular chloride with the impermeant anion gluconate (Wadiche et al., 1995) eliminates this outward current for sEAAT1, sEAAT2A, and sEAAT5A, whereas the inward current at negative potentials was not affected in these three subtypes.

In contrast, sEAAT2B does not exhibit a clear outward current at positive potentials, although the inward current at negative potentials is reduced significantly when external chloride is removed. This reduction of inward current is unlikely to be attributable to a decrease in chloride efflux, because external chloride 
Table 2. Pharmacology of sEAAT subtypes

\begin{tabular}{|c|c|c|c|c|c|c|c|c|}
\hline \multirow[b]{2}{*}{ Drug } & \multicolumn{2}{|l|}{ SEAAT1 } & \multicolumn{2}{|l|}{ SEAAT2A } & \multicolumn{2}{|l|}{ SEAAT2B } & \multicolumn{2}{|l|}{ SEAAT5A } \\
\hline & $I_{\max }$ & $\mathrm{EC}_{50}(\mu \mathrm{M})$ & $I_{\max }$ & $\mathrm{EC}_{50}(\mu \mathrm{M})$ & $I_{\max }$ & $\mathrm{EC}_{50}(\mu \mathrm{M})$ & $I_{\max }$ & $\mathrm{EC}_{50}(\mu \mathrm{M})$ \\
\hline L-Glutamate & (1) & $25.2 \pm 1.7$ & (1) & $39.7 \pm 10.7$ & (1) & $109 \pm 3$ & (1) & $43.1 \pm 3.7$ \\
\hline D-Glutamate & $0.452 \pm 0.202$ & $\geq 10,000$ & $0.133 \pm 0.005$ & $\geq 10,000$ & $0.109 \pm 0.004$ & $\geq 10,000$ & $0.321 \pm 0.008$ & $\geq 10,000$ \\
\hline L-Aspartate & $0.321 \pm 0.004$ & $11.4 \pm 0.8$ & $1.41 \pm 0.17$ & $15.7 \pm 9.0$ & $1.80 \pm 0.10$ & $22.1 \pm 5.5$ & $1.01 \pm 0.04$ & $2.12 \pm 0.62$ \\
\hline D-Aspartate & $0.149 \pm 0.003$ & $15.6 \pm 1.7$ & $1.41 \pm 0.09$ & $22.4 \pm 6.7$ & $1.03 \pm 0.01$ & $42.2 \pm 2.0$ & $0.921 \pm 0.065$ & $5.18 \pm 1.8$ \\
\hline \multirow[t]{2}{*}{ THA } & $0.315 \pm 0.008$ & $37.5 \pm 3.9$ & $0.348 \pm 0.049$ & $21.5 \pm 13.7$ & $0.450 \pm 0.053$ & $29.3 \pm 14.9$ & $0.371 \pm 0.017$ & $5.61 \pm 1.23$ \\
\hline & $I_{\max }$ & $K_{\mathrm{i}}(\mu \mathrm{M})$ & $I_{\max }$ & $K_{\mathrm{i}}(\mu \mathrm{M})$ & $I_{\max }$ & $K_{\mathrm{i}}(\mu \mathrm{M})$ & $I_{\max }$ & $K_{\mathrm{i}}(\mu \mathrm{M})$ \\
\hline Kainate & $(0)$ & $>1000$ & $(0)$ & 31.7 & $(0)$ & 53.2 & $(0)$ & $>1000$ \\
\hline Dihydrokainate & $(0)$ & $>1000$ & $(0)$ & 12.5 & $(0)$ & 19.2 & $(0)$ & $>1000$ \\
\hline
\end{tabular}

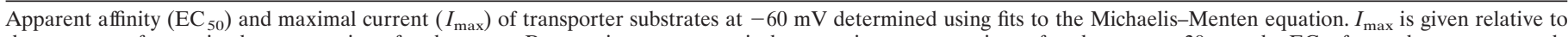

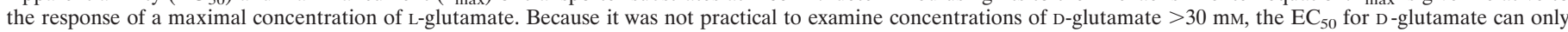

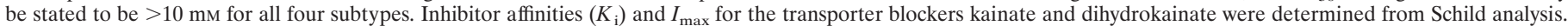

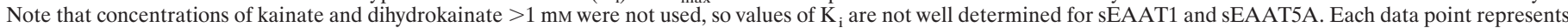
the mean of a least four cells; the error represents SEM.

\section{Table 3. Sodium dependence of sEAAT subtypes}

\begin{tabular}{lll} 
Transporter clone & $\mathrm{Na}^{+} \mathrm{EC}_{50}(\mathrm{~mm})$ & $N$ \\
\hline SEAAT1 & $52.4 \pm 20.6$ & $1.65 \pm 0.36$ \\
SEAAT2A & $27.5 \pm 4.3$ & $1.84 \pm 0.21$ \\
SEAAT2B & $71.8 \pm 1.9$ & $2.12 \pm 0.05$ \\
SEAAT5A & $37.4 \pm 12.6$ & $3.00 \pm 1.57$
\end{tabular}

Apparent affinity $\left(K_{\mathrm{m}}\right)$ and Hill coefficient $(N)$ were determined using the Hill equation on steady-state currents measured in response to $100 \mu \mathrm{M}$ L-glutamate at $-60 \mathrm{mV}$. Each data point represents the mean of five cells; the error represents SEM.

Table 4. Effect of extracellular chloride on uptake

\begin{tabular}{lccc}
$\begin{array}{l}\text { Transporter } \\
\text { clone }\end{array}$ & $\begin{array}{l}\text { nd96 } \\
(\mathrm{fmol} / \mathrm{sec})\end{array}$ & $\begin{array}{l}\text { Chloride-free } \\
(\mathrm{fmol} / \mathrm{sec})\end{array}$ & Charge-to-flux \\
\hline sEAAT1 & $223 \pm 28$ & $215 \pm 19$ & $2.4 \pm 0.3$ \\
sEAAT2A & $262 \pm 30$ & $236 \pm 12$ & $2.9 \pm 0.1$ \\
sEAAT2B & $154 \pm 14$ & $50 \pm 2$ & $2.4 \pm 0.2$ \\
sEAAT5A & $50 \pm 3$ & $65 \pm 4$ & $14.2 \pm 6.0$ \\
sEAAT5B & $30 \pm 4$ & $32 \pm 3$ & $\mathrm{n} / \mathrm{a}$ \\
Uninjected & $28 \pm 2$ & $29 \pm 3$ & $\mathrm{n} / \mathrm{a}$
\end{tabular}

Uptake under voltage clamp in normal (nd96) and chloride-free buffers. Uptake was performed by adding $100 \mu \mathrm{M}\left[{ }^{3} \mathrm{H}\right] \mathrm{L}$-glutamate for $100 \mathrm{sec}$ while the cell was voltageclamped to $-60 \mathrm{mV}$. The right column (charge-to-flux) was determined by dividing the total number of moles of charge transported into the cell (i.e., the integral of the current) by the toal number of moles of $\left[{ }^{3} \mathrm{H}\right] \mathrm{L}$-glutamate transported into the cell. Each data point represents the mean of 10 cells; the error represents SEM.

is removed for $<2 \mathrm{~min}$, whereas it takes several hours of soaking oocytes in chloride-free buffer to decrease intracellular chloride significantly (our unpublished observations).

A more likely possibility is that glutamate transport in sEAAT2B is facilitated by external chloride. To test this hypothesis, we have examined the uptake of radiolabeled glutamate in cells that were exposed either to a normal extracellular solution or to one in which extracellular chloride was replaced with gluconate (Table 4). Ten cells were examined in each condition, and to minimize the effects of differential expression, we injected all oocytes expressing a given transporter clone at the same time with the same batch of RNA. To avoid the effects of different extracellular solutions on the resting potential, we applied $100 \mu \mathrm{M}$ radiolabeled L-glutamate while the oocytes were held under volt- age clamp to $-60 \mathrm{mV}$. Consistent with Figure 6, the uptake by the sEAAT1 and sEAAT2A subtypes was not affected significantly by the removal of extracellular chloride ( $p \geq 0.5$, two-tailed, unpaired $t$ test). Uptake by sEAAT2B, on the other hand, showed a large and significant decrease in the absence of chloride $(p<$ 0.001). Like the glutamate-elicited inward current (Fig. 6), uptake is not blocked completely by the removal of chloride. This suggests that sEAAT2B does not absolutely require external chloride for transport as it does extracellular sodium, but somehow transport is enhanced significantly by the presence of chloride. sEAAT5A shows a marginally significant increase in uptake when extracellular chloride is replaced with gluconate $(p=0.06)$, which might represent some nonindependent interaction between the chloride conductance and the transport of glutamate.

\section{Further examination of the chloride conductance}

We have examined the contribution of the chloride conductance to the total glutamate-elicited current by dialyzing the oocytes in an extracellular solution free of permeant anions for at least $48 \mathrm{hr}$, which eliminates most internal chloride (Wadiche et al., 1995). Figure 7 shows a cross-cell comparison of the current elicited by $100 \mu \mathrm{M}$ L-glutamate among 10 cells that have been soaked in gluconate for $48 \mathrm{hr}$ and another 10 cells that have been kept in a normal chloride solution during the same period. As was shown in Figure 6, removing chloride from the extracellular medium eliminates the outward current present at positive potentials for sEAAT1, sEAAT2A, and sEAAT5A.

At negative potentials, dialyzing cells in gluconate caused the inward currents to become significantly reduced in the subtypes sEAAT1, sEAAT2B, and sEAAT5A. Because removal of external chloride did not reduce uptake in sEAAT1 or sEAAT5A, this result suggests that the efflux of chloride ions may represent a significant fraction of the total current elicited by L-glutamate at this potential range. However, we cannot rule out the possibility that transport of glutamate in these subtypes may be sensitive to intracellular chloride. The glutamate-elicited current in sEAAT5A is abolished almost completely in chloride-free conditions, similar to results reported previously in photoreceptors (Picaud et al., 1995a) and in the EAAT4 and EAAT5 subtypes (Fairman et al., 1995; Arriza et al., 1997). The decrease in inward current present in sEAAT2B can be explained by the sensitivity of sEAAT2B to external chloride (Fig. 6). Therefore, it is difficult 


\section{sEAAT1}

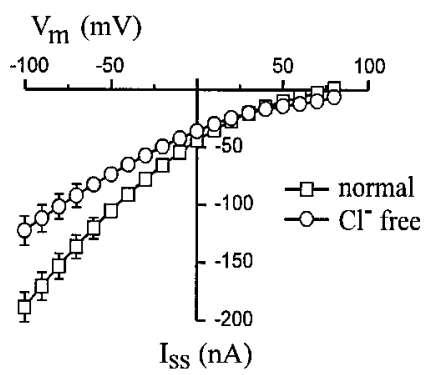

SEAAT2B

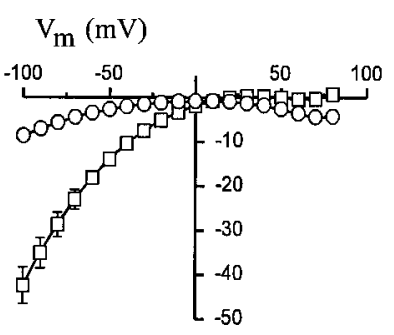

$\mathrm{I}_{\mathrm{SS}}(\mathrm{nA})$
SEAAT2A

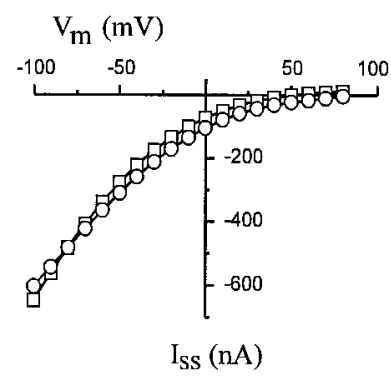

SEAAT5A

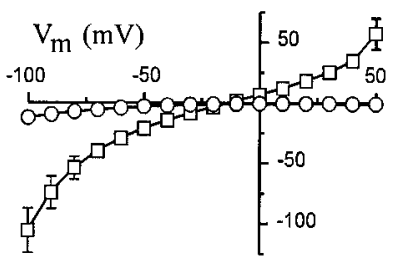

$\mathbf{I}_{\mathrm{SS}}(\mathrm{nA})$

Figure 7. Current-voltage curves in normal cells (open squares) and cells that have been dialyzed in chloride-free buffer for $>48 \mathrm{hr}$ (open circles). Steady-state currents $\left(I_{\mathrm{ss}}\right)$ are elicited in response to $100 \mu \mathrm{M}$ L-glutamate at various membrane potentials $\left(V_{\mathrm{m}}\right)$ in each condition. Data are from two batches of 10 cells each. Error bars indicate SEM; error bars smaller than the symbols are not drawn.

to estimate the relative chloride conductance of SEAAT2B from these experiments.

One method of determining the percentage of glutamateelicited current attributable to the chloride conductance is to examine the charge transferred per molecule of glutamate (the charge-to-flux ratio). The movement of chloride ions through the conductance contributes to the total net charge translocated per transport cycle (Wadiche et al., 1995). This net charge movement can be calculated by integrating the current elicited by radiolabeled glutamate under voltage clamp (i.e., the total charge) and dividing this by the number of glutamate molecules that were taken up into the cell (i.e., the total flux).

At potentials more negative than the chloride equilibrium potential, the passive outward movement of chloride ions through the chloride conductance will increase the charge-to-flux ratio. At $-60 \mathrm{mV}$, this ratio was estimated to be $\sim 2.5$ for the sEAAT1,

Table 5. Contribution of chloride flux to charge movement

\begin{tabular}{lll} 
Transporter clone & $\begin{array}{l}\text { Charge-to-flux ratio } \\
V_{\mathrm{m}}=-80 \mathrm{mV}\end{array}$ & $\begin{array}{l}\text { Charge-to-flux ratio } \\
V_{\mathrm{m}}=E_{\mathrm{C} 1}\end{array}$ \\
\hline sEAAT1 & $2.11 \pm 0.05$ & $1.42 \pm 0.22$ \\
sEAAT2A & $2.60 \pm 0.10$ & $1.51 \pm 0.05$ \\
sEAAT2B & $2.09 \pm 0.07$ & $1.26 \pm 0.07$
\end{tabular}

Charge-to-flux ratio at $-80 \mathrm{mV}$ and at the chloride equilibrium potential $\left(E_{\mathrm{C} 1}\right)$, measured to be $-22 \mathrm{mV}$ in these cells. The change in charge-to-flux ratio at the two potentials is statistically significant ( $p \leq 0.05$ for all three transporters). The charge-to-flux ratio was not measured in sEAAT5A-injected oocytes, because both current and uptake are negligible in this transporter at $E_{\mathrm{C} 1}$. Each data point represents the mean of a least five cells; the error represents SEM.

SEAAT1

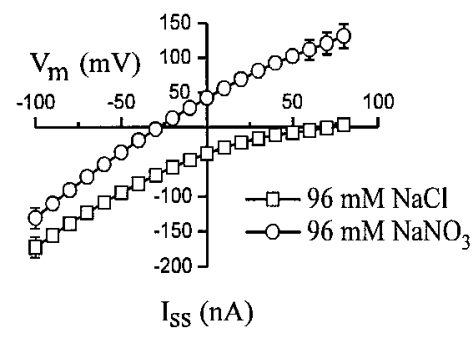

SEAAT2B

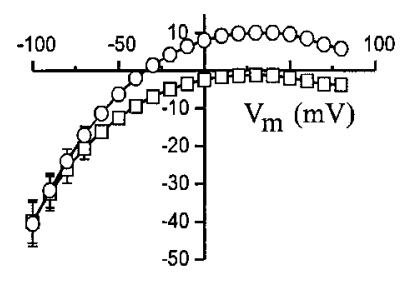

$\mathrm{I}_{\mathrm{sS}}(\mathrm{nA})$
SEAAT2A

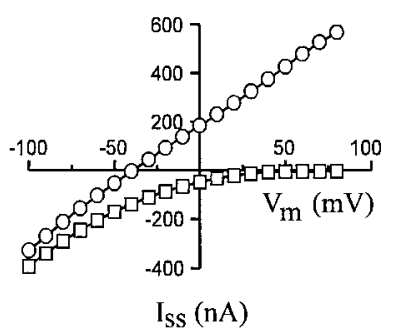

SEAAT5A

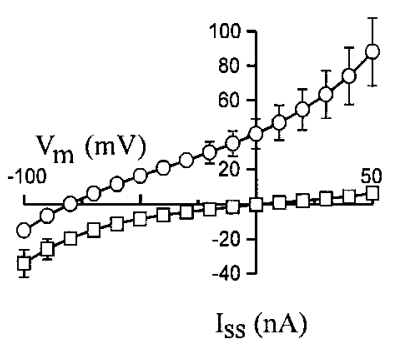

Figure 8. Current-voltage curves in the presence of chloride and nitrate buffer. Shown are steady-state currents $\left(I_{\mathrm{ss}}\right)$ elicited in response to $100 \mu \mathrm{M}$ L-glutamate at various membrane potentials $\left(V_{\mathrm{m}}\right)$ in $96 \mathrm{~mm} \mathrm{NaCl}$ (open squares) or in $96 \mathrm{~mm} \mathrm{NaNO}_{3}$ (open circles). Data under both conditions are from the same five cells. Error bars indicate SEM; error bars smaller than the symbols are not drawn.

sEAAT2A, and sEAAT2B subtypes (Table 4). At the chloride equilibrium potential $\left(E_{\mathrm{Cl}}\right)$ the contribution of the chloride ion flux to the charge-to-flux ratio will be negligible, and, as expected, the ratio becomes significantly smaller (Table $5 ; p \leq 0.05$ for all three transporter subtypes). The difference in charge-to-flux at $-80 \mathrm{mV}$ and $E_{\mathrm{Cl}}$ implies that at $-80 \mathrm{mV} \sim 0.75-1$ chloride ion exits the cell per translocation cycle for these three subtypes. The fact that the charge-to-flux ratio varies with membrane potential also supports the idea that the chloride flux is uncoupled thermodynamically to the transport of glutamate (Wadiche et al., 1995).

In contrast, sEAAT5A has a large charge-to-flux ratio of $14 \pm$ 6 , suggesting that the majority of the inward current at $-60 \mathrm{mV}$ is carried by the passive flux of chloride ions. This is consistent with the data in Figure 7, where in the absence of external chloride the inward current in cells expressing sEAAT5A is nearly abolished.

Previous studies with cloned glutamate transporters from the human motor cortex (Wadiche et al., 1995) and with retinal glial cells (Eliasof and Jahr, 1996) have demonstrated that chaotropic anions have a higher permeability and conductance through the glutamate transporter-associated anion conductance than does chloride. Replacing external chloride with the highly conductive nitrate anion increased the outward current elicited by $100 \mu \mathrm{M}$ L-glutamate at positive potentials in most cases by more than an order of magnitude (Fig. 8). The lack of increasing outward current seen at positive potentials with SEAAT2B may reflect a decrease in glutamate affinity with depolarization (our unpublished observations).

These results indicate that an anionic conductance is present in all four sEAAT subtypes. Furthermore, the reversal potential in external nitrate gives another measure of the relative contribution 
of the anionic current to the total current elicited by glutamate. The more negative the reversal potential, the larger the anionic conductance (Wadiche et al., 1995). The reversal potentials for sEAAT1, sEAAT2A, sEAAT2B, and sEAAT5A are $-27.9 \pm 2.6$, $-39.0 \pm 2.9,-33.8 \pm 2.6$, and $-80.6 \pm 5.2 \mathrm{mV}$, respectively. Again, these data suggest that sEAAT5A has a large anionic conductance associated with the transport of glutamate.

\section{DISCUSSION}

We have isolated five distinct EAAT subtypes from the salamander retina: one EAAT1 subtype, two distinct EAAT2 subtypes, and two distinct members of the retina-specific subclass, EAAT5 (Arriza et al., 1997). No homologs for either EAAT3 or EAAT4 were found in the salamander retina, as determined from multiple screening methods and immunoblots. Similarly, EAAT4 was not detected in human retina (our unpublished observations). EAAC1 (rabbit EAAT3) immunolabeling, on the other hand, has been observed in rat retina (Rauen et al., 1996) and several cold-blooded vertebrates, including salamander (Schultz and Stell, 1996). We were unable to reproduce these results in salamander retina by using a different antibody to human EAAT3. Thus we present the localization and characterization of what appear to be the predominant glutamate transporters in salamander retina.

\section{Immunolocalization}

Like the rat retina, the EAAT1 homolog is located primarily in Müller cells. Unlike the mammalian retina, sEAAT2A is both glial and neuronal, being present in Müller cells as well as in some unidentified bipolar and amacrine cells. sEAAT2B is strictly neuronal, being localized in hyperpolarizing bipolar cells and possibly horizontal cells. Because hyperpolarizing bipolar cells are depolarized in the dark, they release glutamate continuously; a specialized transporter may be necessary in these cells to replenish rapidly depleting internal stores of glutamate and to prevent excess levels of extracellular glutamate. Although there is no known homolog of sEAAT2B in rat or human, it is intriguing to suggest that one is present but currently unidentified. Such a human homolog could account for the kainate-sensitive neuronal glutamate transporter that has been proposed previously (Dowd et al., 1996) because EAAT2 is non-neuronal in brain (Rothstein et al., 1994; Lehre et al., 1995).

The two homologs of EAAT5, sEAAT5A and sEAAT5B, are both neuronal and glial in origin. The bright staining in the OPL may represent photoreceptor terminals or DBC dendrites or both, because both cell types possess transporters that are functionally similar to sEAAT5A.

\section{Functional characterization}

The four transporters studied in this paper share many of the pharmacological and ionic dependency properties common to the human glutamate transporter clones described previously (Arriza et al., 1994, 1997; Fairman et al., 1995). However, the five transporters have several distinguishing features that may make it possible to identify transporter subtypes when electrophysiological experiments are performed in the salamander retina.

Several pieces of evidence suggest that, similar to EAAT4 and EAAT5 (Fairman et al., 1995; Arriza et al., 1997), the current elicited by application of L-glutamate in the transporter sEAAT5A is attributable almost entirely to the passive flux of chloride ions through the associated chloride conductance. First, when internal chloride is diminished significantly and external chloride is removed, the L-glutamate-elicited current is nearly abolished. Second, the charge transferred per molecule of glutamate is $\sim 14$; based on a transporter stoichiometry of two charges per molecule of glutamate, these data suggest that $\sim 85 \%$ of the current is carried by chloride ions. Finally, in the presence of external nitrate, the reversal potential is approximately $-80 \mathrm{mV}$, which is $40-50 \mathrm{mV}$ more negative than what was observed for the other transporters.

sEAAT1 and sEAAT2A also appear to have a significant chloride conductance. Both subtypes have an L-glutamate-elicited outward current that is eliminated by the removal of external chloride, and both have large outward currents when external chloride is replaced with nitrate. At $-80 \mathrm{mV}$, up to one chloride ion passively exits the cell per translocation cycle.

sEAAT2B is the first glutamate transporter cloned that shows a sensitivity to external chloride. This sensitivity is made evident by the significant reduction in both the L-glutamate-elicited inward current and the transport of radiolabeled glutamate when external chloride is removed. Chloride-sensitive glutamate transporters have been described in synaptosomes from rat brain and rabbit retina (Kuhar and Zarbin, 1978; Mitchell and Redburn, 1988). However, these transporters are sodium-independent, relatively unaffected by aspartate, and are inhibited by L-2-amino4-phosphonobutyrate (APB) and quisqualate (Zaczek et al., 1987; Mitchell and Redburn, 1988). Furthermore, this activity is likely to be attributable to a cystine/glutamate exchanger molecule (Bannai, 1986; Kato et al., 1993). In contrast, we found that sEAAT2B is sodium-dependent, transports both isoforms of aspartate, and is not affected by quisqualate or APB (data not shown). Thus, sEAAT2B may be the first example of a chlorideand sodium-dependent high-affinity glutamate transporter. In addition to a chloride sensitivity, sEAAT2B also has an anion conductance, because a measurable L-glutamate-elicited outward current was present when external chloride was replaced with nitrate.

\section{Comparison with native retinal transport}

It is instructive to compare transporter subtype function and localization with studies of native glutamate transport in retinal cells. We found that Müller cells possess the glutamate transporter subtypes sEAAT1, sEAAT2A, sEAAT5A, and sEAAT5B. It would be difficult to distinguish multiple transport activities with multiple affinities, given the similar apparent affinities for glutamate among the four subtypes. However, of the four subtypes in Müller cells, only sEAAT2A is sensitive to micromolar concentrations of dihydrokainate, and $500 \mu \mathrm{M}$ dihydrokainate inhibits glutamate-elicited currents in Müller cells by only $15 \%$ (Barbour et al., 1991). Furthermore, the glutamate-elicited current in sEAAT5A is predominantly a chloride current, whereas only a small but measurable chloride conductance associated with glutamate transport has been described in Müller cells (Billups et al., 1996; Eliasof and Jahr, 1996). Thus, if we assume functional independence among the glutamate transporters in Müller cells, it is likely that sEAAT1 represents the majority of glutamate transporters functioning in Müller cells.

Cone and rod photoreceptors both have glutamate-elicited currents that have the pharmacology and ionic dependence of glutamate transporters, but, like sEAAT5A, the currents appear to be carried mainly by chloride ions (Sarantis et al., 1988; Eliasof and Werblin, 1993; Picaud et al., 1995a; Grant and Werblin, 1996). Because the glutamate current in photoreceptors was found almost exclusively in the terminal regions (Sarantis et al., 
1988; Grant and Werblin, 1996), the greatest concentration of glutamate transporters in photoreceptors is expected to be in the OPL. sEAAT5A staining is indeed intense in this region. In addition, $1 \mathrm{mM}$ dihydrokainate blocked the response to $100 \mu \mathrm{M}$ glutamate in both cones and rods by 42 and 50\%, respectively, whereas sEAAT5A is insensitive to dihydrokainate at this concentration. Thus, at least $40-50 \%$ of the glutamate response in photoreceptors must be attributable to an EAAT2 homolog: sEAAT2A, sEAAT2B, or perhaps both. Both of these transporters exhibit significant staining in the OPL, where photoreceptor synaptic processes terminate, but on the basis of immunolocalization it seems more likely that sEAAT2B is in bipolar cell dendrites and sEAAT2A is in photoreceptor terminals.

Depolarizing $(\mathrm{ON})$ bipolar cells from white perch retina also have been reported to possess glutamate transporters that resemble those in photoreceptors (Grant and Dowling, 1995) The sodium-dependent glutamate-elicited current in these cells is carried mainly by chloride ions and is relatively insensitive to dihydrokainate. The transporters are localized to the dendrites, which ramify in the OPL. All of the four transporters characterized in this paper can be found in the OPL to varying degrees. Both sEAAT2A and sEAAT2B appear to be localized in bipolar cells, but they are dihydrokainate-sensitive. Furthermore, the current through these two subtypes is not carried mainly by chloride ions. Thus, if ON bipolar cells in the salamander retina also possess postsynaptic transporters like those found in white perch, they are more likely to be sEAAT5A.

Our immunolocalization studies suggest that amacrine and ganglion cells, and possibly horizontal cells, likewise express glutamate transporters. Physiological studies have not yet examined this possibility, but the use of more permeant anions such as nitrate may help to resolve such currents in the future.

\section{Summary}

In summary, we have identified five distinct glutamate transporters in the salamander retina. It is not clear why so many different glutamate transporters exist. A bewildering variety of subtypes can be found with many membrane proteins such as AMPA receptors and potassium channels, and thus perhaps such diversity is more the rule than the exception. Differences in localization and functional properties, however, suggest that the different transporters must play distinct roles. Perhaps most significantly, the five transporters differ in the relative amount of chloride conductance. Given the importance of the chloride conductance in regulating glutamate release from cone photoreceptors (Picaud et al., 1995b) and in synaptic transmission to depolarizing bipolar cells (Grant and Dowling, 1995), these differences may be of great physiological importance. Furthermore, multiple subtypes coexist in a single cell; by bringing together a variety of transporter subtypes, it may be possible to shape the response of a given cell to the presence of extracellular glutamate in subtle ways.

\section{REFERENCES}

Arriza JL, Kavanaugh MP, Fairman WA, Wu Y-N, Murdoch GH, North RA, Amara SG (1993) Cloning and expression of a human neutral amino acid transporter with structural similarity to the glutamate transporter gene family. J Biol Chem 268:15329-15332.

Arriza JL, Fairman WA, Wadiche JI, Murdoch GH, Kavanaugh MP, Amara SG (1994) Functional comparisons of three glutamate transporter subtypes cloned from human motor cortex. J Neurosci 14:5559-5569.

Arriza JL, Eliasof S, Kavanaugh MP, Amara SG (1997) EAAT5, a retinal glutamate transporter coupled to a chloride conductance. Proc Natl Acad Sci USA 95:4155-4160.
Bannai S (1986) Exchange of cystine and glutamate across plasma membrane of human fibroblasts. J Biol Chem 261:2256-2263.

Barbour B, Brew H, Attwell D (1991) Electrogenic uptake of glutamate and aspartate in glial cells isolated from the salamander retina. J Physiol (Lond) 436:169-193.

Barrish ME (1983) A transient calcium-dependent chloride current in the immature Xenopus oocyte. J Physiol (Lond) 342:309-325.

Billups B, Rossi D, Attwell D (1996) Anion conductance behavior of the glutamate uptake carrier in salamander retinal glial cells. J Neurosci 16:6722-6731.

Brew H, Attwell D (1987) Electrogenic glutamate uptake is a major current carrier in the membrane of axolotl retinal glial cells. Nature 327:707-709.

Conradt M, Storck T, Stoffel W (1995) Localization of N-glycosylation sites and functional role of the carbohydrate units of GLAST-1, a cloned rat brain L-glutamate/liter-aspartate transporter. Eur J Biochem 229:682-687.

Derouiche A, Rauen T (1995) Coincidence of L-glutamate/literaspartate transporter (GLAST) and glutamine synthetase (GS) immunoreactions in retinal glia: evidence for coupling of GLAST and GS in transmitter clearance. J Neurosci Res 42:131-143.

Dowd LA, Coyle AJ, Rothstein JD, Pritchett DB, Robinson MB (1996) Comparison of $\mathrm{Na}^{+}$-dependent glutamate transport activity in synaptosomes, C6 glioma, and Xenopus oocytes expressing excitatory amino acid carrier 1 (EAAC1). Mol Pharmacol 49:465-473.

Eliasof S, Jahr CE (1996) The retinal glial cell glutamate transporter is coupled to an anionic conductance. Proc Natl Acad Sci USA 93:4153-4158.

Eliasof S, Werblin F (1993) Characterization of the glutamate transporter in retinal cones of the salamander retina. J Neurosci 13:402-411.

Euler T, Wässle H (1995) Immunocytochemical identification of cone bipolar cells in the rat retina. J Comp Neurol 361:461-478.

Fairman WA, Vandenberg RJ, Arriza JL, Kavanaugh MP, Amara SG (1995) An excitatory amino-acid transporter with properties of a ligand-gated chloride channel. Nature 75:599-603.

Grant GB, Dowling JE (1995) A glutamate-activated chloride current in cone-driven ON bipolar cells of the white perch retina. J Neurosci 15:3852-3862.

Grant GB, Dowling JE (1996) ON bipolar cell responses in the teleost retina are generated by two distinct mechanisms. J Neurophysiol 76:3842-3849.

Grant GB, Werblin FS (1996) A glutamate-elicited chloride current with transporter-like properties in rod photoreceptors of the tiger salamander. Vis Neurosci 13:135-144.

Grünert U, Martin PR, Wässle H (1994) Immunocytochemical analysis of bipolar cells in the macaque monkey retina. J Comp Neurol 348:607-627.

Kanai Y, Hediger MA (1992) Primary structure and functional characterization of a high affinity glutamate transporter. Nature 360:467-471.

Kato S, Ishita S, Sugawara K, Mawatari K (1993) Cystine/glutamate antiporter expression in retinal Müller cells: implications for DL- $\alpha$ aminoadipate toxicity. Neuroscience 57:473-482.

Kuhar MJ, Zarbin MA (1978) Synaptosomal transport: a chloride dependence for choline, GABA, glycine and several other compounds. J Neurochem 31:251-256.

Lehre KP, Levy LM, Ottersen OP, Storm-Mathisen J, Danbolt NC (1995) Differential expression of two glial glutamate transporters in the rat brain: quantitative and immunocytochemical observations. J Neurosci 15:1835-1853.

Lehre KP, Davanger S, Danbolt NC (1997) Localization of the glutamate transporter protein GLAST in rat retina. Brain Res 744:129-137.

Liepe BA, Stone C, Koistinaho J, Copenhagen DR (1994) Nitric oxide synthase in Müller cells and neurons of salamander and fish retina. J Neurosci 14:7641-7654.

Massey SC (1990) Cell types using glutamate as a neurotransmitter in the vertebrate retina. In: Progress in retinal research, Vol 9 (Osborne NN, Chader G, eds), pp 399-425. London: Pergamon.

Melikian HE, McDonald JK, Gu H, Rudnick G, Moore KR, Blakely RD (1994) Human norepinephrine transporter. Biosynthetic studies using a site-directed polyclonal antibody. J Biol Chem 269:12290-12297.

Mitchell CK, Redburn DA (1988) AP4 inhibits chloride-dependent binding and uptake of $\left[{ }^{3} \mathrm{H}\right]$ glutamate in rabbit retina. Brain Res 459:298-311.

Nguyen T, Amara SG (1996) N-linked oligosaccharides are required for cell surface expression of the norepinephrine transporter but do not influence substrate or inhibitor recognition. J Neurochem 67:645-655. 
Picaud S, Larsson HP, Grant GB, Lecar H, Werblin FS (1995a) Glutamate-gated chloride channel with glutamate-transporter-like properties in cone photoreceptors of the tiger salamander. J Neurophysiol 74:1760-1771.

Picaud S, Larsson HP, Wellis DP, Lecar H, Werblin FS (1995b) Cone photoreceptors respond to their own glutamate release in the tiger salamander. Proc Natl Acad Sci USA 92:9417-9421.

Pines G, Danbolt NC, Bjoras M, Zhang Y, Bendahan A, Eide L, Koespell H, Storm Mathisen J, Seeberg E, Kanner BI (1992) Cloning and expression of a rat brain L-glutamate transporter. Nature 360:464-467.

Rauen T, Kanner BI (1994) Localization of the glutamate transporter GLT-1 in rat and macaque monkey retinae. Neurosci Lett 169:137-140.

Rauen T, Rothstein JD, Wässle H (1996) Differential expression of three glutamate transporter subtypes in the rat retina. Cell Tissue Res 286:325-336.

Rothstein JD, Martin L, Levey AI, Dykes-Hoberg M, Jin L, Wu D, Nash N, Kuncl RW (1994) Localization of neuronal and glial glutamate transporters. Neuron 13:713-725.

Sarantis M, Everett K, Attwell D (1988) A presynaptic action of glutamate at the cone output synapse. Nature 332:451-453.
Schultz K, Stell WK (1996) Immunocytochemical localization of the high-affinity glutamate transporter, EAAC1, in the retina of representative vertebrate species. Neurosci Lett 211:191-194.

Schwartz EA, Tachibana M (1990) Electrophysiology of glutamate and sodium co-transport in a glial cell of the salamander retina. J Physiol (Lond) 426:43-80.

Storck T, Schulte S, Hofmann K, Stoffel W (1992) Structure, expression, and functional analysis of a $\mathrm{Na}^{+}$-dependent glutamate/aspartate transporter from rat brain. Proc Natl Acad Sci USA 89:10955-10959.

Tachibana M, Kaneko A (1988) L-Glutamate-induced depolarization in solitary photoreceptors: a process that may contribute to the interaction between photoreceptors in situ. Proc Natl Acad Sci USA 85:5315-5319.

Wadiche JI, Amara SG, Kavanaugh MP (1995) Ion fluxes associated with excitatory amino acid transport. Neuron 15:721-728.

Zaczek R, Balm M, Arlis S, Drucker H, Coyle JT (1987) Quisqualatesensitive, chloride-dependent transport of glutamate into rat brain synaptosomes. J Neurosci Res 18:425-431.

Zerangue N, Kavanaugh MP (1996) Flux coupling in a neuronal glutamate transporter. Nature 383:634-637. 